\title{
Ion channelopathies in human induced pluripotent stem cell derived cardiomyocytes: a dynamic clamp study with virtual $I_{K 1}$
}

\author{
Rosalie M. E. Meijer van Putten ${ }^{1}$, Isabella Mengarelli' ${ }^{2}, K_{a o m e i ~ G u a n}{ }^{3}$, Jan G. Zegers' , \\ Antoni C. G. van Ginneken ${ }^{1}$, Arie O. Verkerk ${ }^{1}$ and Ronald Wilders ${ }^{1 *}$ \\ ${ }^{1}$ Department of Anatomy, Embryology and Physiology, Academic Medical Center, University of Amsterdam, Amsterdam, Netherlands \\ ${ }^{2}$ Department of Experimental Cardiology, Academic Medical Center, University of Amsterdam, Amsterdam, Netherlands \\ ${ }^{3}$ Department of Cardiology and Pneumology, Georg-August-University of Göttingen, Göttingen, Germany
}

Edited by:

Maria Cristina D'Adamo, University of Perugia, Italy

\section{Reviewed by:}

Erik A. Fransén, Royal Institute of

Technology, Sweden

Phanindra Velisetty, Rutgers New

Jersey Medical School, USA

${ }^{*}$ Correspondence:

Ronald Wilders, Department of Anatomy, Embryology and

Physiology, Academic Medical

Center, University of Amsterdam,

Meibergdreef 15, $1105 \mathrm{AZ}$

Amsterdam, Netherlands

e-mail:r.wilders@amc.uva.nl
Human induced pluripotent stem cell derived cardiomyocytes (hiPSC-CMs) are widely used in studying basic mechanisms of cardiac arrhythmias that are caused by ion channelopathies. Unfortunately, the action potential profile of hiPSC-CMs-and consequently the profile of individual membrane currents active during that action potential-differs substantially from that of native human cardiomyocytes, largely due to almost negligible expression of the inward rectifier potassium current $\left(I_{k_{1}}\right)$. In the present study, we attempted to "normalize" the action potential profile of our hiPSC-CMs by inserting a voltage dependent in silico $\mathrm{I}_{\mathrm{K} 1}$ into our hiPSC-CMs, using the dynamic clamp configuration of the patch clamp technique. Recordings were made from single hiPSC-CMs, using the perforated patch clamp technique at physiological temperature. We assessed three different models of $I_{K 1}$, with different degrees of inward rectification, and systematically varied the magnitude of the inserted $I_{K 1}$. Also, we modified the inserted $I_{K 1}$ in order to assess the effects of loss- and gain-of-function mutations in the KCNJ2 gene, which encodes the Kir2.1 protein that is primarily responsible for the $I_{\mathrm{K} 1}$ channel in human ventricle. For our experiments, we selected spontaneously beating hiPSC-CMs, with negligible $I_{K}$ as demonstrated in separate voltage clamp experiments, which were paced at $1 \mathrm{~Hz}$. Upon addition of in silico $\mathrm{I}_{\mathrm{K} 1}$ with a peak outward density of $4-6 \mathrm{pA} / \mathrm{pF}$, these hiPSC-CMs showed a ventricular-like action potential morphology with a stable resting membrane potential near $-80 \mathrm{mV}$ and a maximum upstroke velocity $>150 \mathrm{~V} / \mathrm{s}$ $(n=9)$. Proarrhythmic action potential changes were observed upon injection of both loss-of-function and gain-of-function $I_{\mathrm{K} 1}$, as associated with Andersen-Tawil syndrome type 1 and short QT syndrome type 3 , respectively $(n=6)$. We conclude that injection of in silico $\mathrm{I}_{\mathrm{K} 1}$ makes the hiPSC-CM a more reliable model for investigating mechanisms underlying cardiac arrhythmias.

Keywords: action potentials, Andersen-Tawil syndrome, cardiac ion channelopathies, inward rectifier potassium channel, KCNJ2 gene, Kir2.1 protein, patch clamp, short QT syndrome 3

\section{INTRODUCTION}

Long QT syndrome (LQTS), with an estimated prevalence of 1:2000 (Schwartz et al., 2009), is the most commonly encountered inherited arrhythmia disorder in clinical practice $(\approx 35 \%)$, whereas short QT syndrome (SQTS) is the least common one $(\approx 2 \%)$ (Hocini et al., 2014). Both can be related to mutations in the KCNJ2 gene, which encodes the Kir2.1 member of the Kir2 protein family. Tetramers of Kir2 proteins constitute the cardiac inward rectifier potassium channel, which is responsible for maintaining a stable resting membrane potential in the working myocardium by conducting the inward rectifier potassium current $\left(\mathrm{I}_{\mathrm{K} 1}\right)$ (Dhamoon and Jalife, 2005). $\mathrm{I}_{\mathrm{K} 1}$ is also largely responsible for the final repolarization phase of the ventricular action potential (Shimoni et al., 1992). In human ventricle, Kir2.1 is by far the most abundant Kir2.x protein (92\%; Kir2.2: 7\%; Kir2.3: $<1 \%$ ). The same holds true for human atrium, but figures are somewhat different (81\%; Kir2.2: 9\%; Kir2.3: 10\%), which may explain the less pronounced rectification of $\mathrm{I}_{\mathrm{K} 1}$ in human atrium (Wang et al., 1998).

A loss-of-function mutation in KCNJ2 may result in ventricular arrhythmias and abnormalities on the ECG, including prolongation of the QT interval. This explains the classification as LQTS type 7 (LQT7; Tristani-Firouzi et al., 2002). However, the expression of Kir2.1 channels is not limited to the heart and lossof-function mutations in KCNJ2 may also lead to periodic paralysis, dysmorphic features and neurocognitive problems. Given the multisystem nature of the disorder associated with suppression of Kir2.1 channel function and the only modest QT prolongation, if 
any, Andersen-Tawil syndrome (ATS) has become the preferred name (Nguyen et al., 2013). With an estimated prevalence in the order of 1:100,000, ATS is rare. A mutation in KCNJ2 can be identified in 60-70\% of all ATS patients (ATS type 1, ATS1).

Gain-of-function mutations in KCNJ2 are even more rare. They may cause familial atrial fibrillation type 3 (AF3) as well as SQTS type 3 (SQT3). The increase in $\mathrm{I}_{\mathrm{K} 1}$ results in a shortening of the repolarization phase of the cardiac action potential and a predisposition to supraventricular and ventricular arrhythmias (Patel et al., 2010). Only a few SQT3 mutations have been identified thus far (Priori et al., 2005; Hattori et al., 2012; Deo et al., 2013; Ambrosini et al., 2014). The E299V (Deo et al., 2013) and M301K (Hattori et al., 2012) mutations both lead to a largely abolished rectification of $\mathrm{I}_{\mathrm{K} 1}$, which explains the shortened action potential and QT interval.

Unfortunately, the availability of freshly isolated human cardiomyocytes (CMs) for research is highly limited. This holds for control myocytes and even more so for myocytes from patients with channelopathies. Culturing human CMs or mammalian CMs in general is not an option because these cells lose specific morphologic and functional properties in culture (Mitcheson et al., 1998; Louch et al., 2011). For example, there is a significant decrease in $\mathrm{I}_{\mathrm{K} 1}$ over time.

Functional aspects of LQTS and related monogenic disorders have been investigated by expressing mutant channels in heterologous expression systems like Xenopus oocytes, human embryonic kidney (HEK)-293 cells, and Chinese hamster ovary (CHO) cells. However, results from expression studies should be interpreted with care, as illustrated by the essential differences in results obtained from Xenopus and HEK-293 expression systems for the $1795 \mathrm{insD}$ mutation in SCN5A, encoding the pore forming subunit of the fast sodium channel (Remme et al., 2008). Another, highly remarkable illustration comes from the pathological D1275N mutation in SCN5A, which produces nearnormal currents in multiple heterologous expression experiments (Watanabe et al., 2011).

The generation of transgenic mice allows the study of mutant channel behavior in the native myocyte environment. However, the electrophysiology of murine CMs is essentially different from that in human, with differences in action potential profile and underlying membrane currents and, of course, in heart rate, limiting the usefulness of transgenic mouse models for the research of cardiac ion channelopathies (Nerbonne, 2014).

CMs derived from human induced pluripotent stem cells (hiPSC-CMs), building on the seminal work of Takahashi et al. (2007), are a promising new tool in the research of cardiac ion channelopathies (Zhang et al., 2009; Narsinh et al., 2011). Cell lines can be disease and species dependent, thus not only allowing research on the effects of channelopathies in their natural setting, but also on the role of genetic background. Over the past years, hiPSC-CMs have been used in a growing number of studies on channelopathies, as reviewed by Hoekstra et al. (2012), Priori et al. (2013), Sinnecker et al. (2013), Knollmann (2013), Sallam et al. (2014), Savla et al. (2014), and Shinnawi and Gepstein (2014).

An essential problem with hiPSC-CMs is their immature phenotype. In general, hiPSC-CMs demonstrate spontaneous activity with a depolarized maximum diastolic potential (MDP), a low maximum upstroke velocity $\left[(\mathrm{dV} / \mathrm{dt})_{\max }\right]$ and a highly variable action potential duration (Hoekstra et al., 2012). If quiescent, their resting membrane potential (RMP) is depolarized in comparison with that of native working CMs. The depolarized MDP or RMP of hiPSC-CMs results in inactivation and thus a lower functional availability of fast sodium channels, which may explain, at least in part, their low upstroke velocity. Similarly, functional availability of transient outward potassium channels may be reduced through inactivation at depolarized potentials (Cordeiro et al., 2013). Ultrastructurally, there are also differences between hiPSC-CMs and native CMs. In particular, hiPSC-CMs exhibit a poorly developed sarcoplasmic reticulum and a lack of T tubules (Gherghiceanu et al., 2011), which is associated with immaturity of the $\mathrm{Ca}^{2+}$ homeostasis (Louch et al., 2015).

A common observation in hiPSC-CMs is their virtual lack of $\mathrm{I}_{\mathrm{K} 1}$ (Hoekstra et al., 2012), even if the age post-differentiation is raised to 120 days (Doss et al., 2012), which readily explains their depolarized MDP or RMP. Several attempts have been proposed to "mature" hiPSC-CMs through an increase in $\mathrm{I}_{\mathrm{K} 1}$. One approach is to mediate the expression of Kir2.1 channels through adenoviral transduction, as Lieu et al. (2013) demonstrated for CMs derived from human embryonic stem cells. Another approach was put forward by Bett et al. (2013). In their pilot study, they increased $\mathrm{I}_{\mathrm{K} 1}$ in hiPSC-CMs through "electronic expression," using the dynamic clamp technique (Wilders, 2006), and demonstrated that the action potential profile could be improved by eliminating spontaneous activity and establishing a physiological RMP. Of note, their whole cell patch clamp experiments were carried out at room temperature and with an $\mathrm{I}_{\mathrm{K} 1}$ magnitude that was independent of cell size.

In the present study, we increased the expression level of $\mathrm{I}_{\mathrm{K} 1}$ in our hiPSC-CMs by adding in silico $\mathrm{I}_{\mathrm{K} 1}$ using a dynamic patch clamp approach. We made perforated patch clamp recordings from a series of hiPSC-CMs at a physiological temperature, systematically varying the magnitude of $\mathrm{I}_{\mathrm{K} 1}$ and assessing the effects of multiple models of $\mathrm{I}_{\mathrm{K} 1}$, with different degrees of rectification. Also, we assessed the effects of both loss-of-function and gainof-function mutations in $\mathrm{I}_{\mathrm{K} 1}$ by modifying our in silico $\mathrm{I}_{\mathrm{K} 1}$, thus simulating ATS1 and SQT3, respectively.

\section{MATERIALS AND METHODS CELL PREPARATION}

\section{Generation of human induced pluripotent stem cells}

Skin punch biopsies were taken from adult healthy volunteers, as approved by the ethics committee of the University Medical Center of the Georg-August-University of Göttingen. To generate human induced pluripotent stem cells (hiPSCs) from primary fibroblasts derived from these skin biopsies, the lentiviral STEMCCA system was used as previously described (Streckfuss-Bömeke et al., 2013). Briefly, $1.5 \times 10^{4}$ human primary fibroblasts were plated onto a well of a 12-well plate 1 day prior to the transduction. The viruses were produced in-house in HEK cells and the supernatant of virus productions were used. The cells were transduced in fibroblast growth medium composed of DMEM (Invitrogen) supplemented with $10 \%$ heat-inactivated fetal calf serum (FCS, Lonza), L-glutamine 
( $2 \mathrm{mM}$, Invitrogen), $1 \times$ non-essential amino acids (NEAA, Invitrogen), $\beta$-mercaptoethanol ( $\beta$-ME, $50 \mu \mathrm{M}$, Serva), and penicillin $(50 \mathrm{U} / \mathrm{mL}) /$ streptomycin $(50 \mu \mathrm{g} / \mathrm{mL})$ at $37^{\circ} \mathrm{C}$ with $5 \% \mathrm{CO}_{2}$ atmosphere. Additionally, polybrene $(2 \mu \mathrm{g} / \mathrm{mL}$, Sigma-Aldrich) was applied to the medium. After $24 \mathrm{~h}$ at $37^{\circ} \mathrm{C}$, the virus particles were removed by washing the cells three times with DMEM and the cells were cultured in fibroblast growth medium for another 5 days. The cells were then transferred onto $6-\mathrm{cm}$ cell culture dishes pre-coated with mitomysin C-inactivated mouse embryonic fibroblasts (MEFs) at a ratio of 1:4 and the medium was changed to hES-medium composed of DMEM/F12 (Invitrogen) containing 20\% Knockout serum replacement (Invitrogen), L-glutamine $(2 \mathrm{mM}), 1 \times \mathrm{NEAA}, \beta$-ME $(50 \mu \mathrm{M})$, and basic fibroblast growth factor (bFGF, $10 \mathrm{ng} / \mathrm{mL}$, TEBU). The colonies with typical morphology for human pluripotent stem cells first appeared 4-6 weeks later and were mechanically isolated. The isolated hiPSC colonies were then expanded on MEFs in hES-medium.

\section{Culture of hiPSCs and differentiation to cardiomyocytes}

Adherent cultures of hiPSCs were adapted to feeder-free conditions of growth in matrigel-coated dishes, in presence of chemically defined medium (mTeSR, StemCell Technologies). Differentiation of hiPSCs to CMs was performed by following the small molecules-mediated canonical Wnt pathway modulation exactly as previously described (Lian et al., 2013). Briefly, undifferentiated adherent cultures were treated with CHIR99021 (12 $\mu \mathrm{M}$, Selleckchem) for $24 \mathrm{~h}$ on day 1 , followed by Wnt pathway inhibition by IWP4 ( $5 \mu \mathrm{M}$, Stemgent) on day 4 and 5 of differentiation. After culturing for 7 days in RPMI medium with B27 (Invitrogen/Life Technologies), insulin was added and differentiating cells were cultured until day 30. Enrichment for CMs was performed by adding $4 \mathrm{mM}$ lactic acid in substitution of glucose (Tohyama et al., 2013) for 6 days.

\section{Dissociation of cardiomyocytes}

Single hiPSC-CMs were obtained by enzymatic dissociation following a protocol somewhat similar to one previously described for the isolation of rabbit sinoatrial nodal cells (Verkerk et al., 2009). The cardiomyocyte-enriched cultures were transferred manually to a low- $\mathrm{Ca}^{2+}$ Tyrode solution, containing (in $\mathrm{mM}$ ): $140 \mathrm{NaCl}, 5.4 \mathrm{KCl}, 0.01 \mathrm{CaCl}_{2}, 1.0 \mathrm{MgCl}_{2}, 5.5$ glucose, 5.0 HEPES, and 14.1 creatine; $\mathrm{pH} 7.4(\mathrm{NaOH})$. After an incubation of $10 \mathrm{~min}$ at room temperature, Liberase $(0.04 \mathrm{mg} / \mathrm{mL}$, Roche Chemicals) and Elastase $(0.01 \mathrm{mg} / \mathrm{mL}$, Serva) were added and cells were incubated for $10 \mathrm{~min}$ at $37^{\circ} \mathrm{C}$ while shaking gently. Subsequently, supernatant was removed and a Kraft-Brühe solution $\left(37^{\circ} \mathrm{C}\right)$ was added to stop the enzymatic dissociation. This Kraft-Brühe solution contained (in $\mathrm{mM}$ ): $85 \mathrm{KCl}, 30 \mathrm{~K}_{2} \mathrm{HPO}_{4}$, $5.0 \mathrm{MgSO}_{4}$, 5.5 glucose, 5.0 pyruvic acid, 5.0 creatine, 30 taurine, 5.0 Na-hydroxybutyric acid, 5.0 succinic acid, 2.0 Na $\mathrm{Na}_{2}$ ATP and $1 \% \mathrm{BSA} ; \mathrm{pH} 7.2(\mathrm{KOH})$. Dissociation to single cells was achieved by a short period of firm manual shaking, after which the cell suspensions were incubated at $37^{\circ} \mathrm{C}$ for $10 \mathrm{~min}$ while shaking. hiPSC-CMs were centrifuged and resuspended in basic differentiation medium, i.e. RPMI medium supplemented with B27, to which $20 \%$ FBS and penicillin $(50 \mathrm{U} / \mathrm{mL}) /$ streptomycin $(50 \mu \mathrm{g} / \mathrm{mL})$ were added, and plated on $0.1 \%$ gelatin-coated glass coverslips. Medium was replaced with serum-free medium after $24 \mathrm{~h}$ and subsequently with antibiotic-free medium every 3-4 days. Electrophysiological analysis was performed 10-15 days after dissociation.

\section{ELECTROPHYSIOLOGY \\ Electrophysiological recordings}

Electrophysiological recordings were made from single spontaneously active hiPSC-CMs through the amphotericin-B perforated patch clamp technique, using an Axopatch 200B amplifier (Molecular Devices, Sunnyvale, CA). Cells selected for experiments showed spontaneous beating upon visual inspection. The cell chamber was put on the stage of a Nikon Eclipse TE2000-U inverted phase-contrast microscope. Cells were superfused with the above Tyrode solution with $1.8 \mathrm{mM} \mathrm{CaCl}_{2}$ and without creatine. Low-resistance borosilicate glass pipettes (1.5-2.5 $\mathrm{M} \Omega$ ) were filled with a solution containing (in $\mathrm{mM}$ ): $125 \mathrm{~K}$-gluconate, 20 $\mathrm{KCl}, 5 \mathrm{NaCl}, 10 \mathrm{HEPES}$, and 0.44 amphotericin-B; $\mathrm{pH} 7.2(\mathrm{KOH})$. Series resistance was compensated by $\geq 80 \%$ and potentials were corrected for the estimated liquid junction potential of $-15 \mathrm{mV}$.

Voltage control, data acquisition, and data analysis were accomplished using custom-written software running on an Apple Macintosh G4 computer equipped with a National Instruments NB-MIO-16 twelve-bit data acquisition board. Action potentials were low-pass filtered $(5 \mathrm{kHz})$ and digitized at $4 \mathrm{kHz}$. Membrane currents were filtered and digitized at 2 and $5 \mathrm{kHz}$, respectively. Cell membrane capacitance was estimated by dividing the time constant of the decay of the capacitive transient in response to $5 \mathrm{mV}$ hyperpolarizing voltage clamp steps from $-40 \mathrm{mV}$ by the series resistance, and amounted to $25 \pm 4$ $\mathrm{pF}$ (mean \pm SEM, $n=9$ ). All experiments were carried out at a temperature of $35-37^{\circ} \mathrm{C}$.

We analyzed various action potential characteristics, including maximum diastolic potential (MDP), action potential amplitude (APA), maximal upstroke velocity $\left[(\mathrm{dV} / \mathrm{dt})_{\max }\right]$, and action potential duration at $90 \%$ repolarization $\left(\mathrm{APD}_{90}\right)$. Action potential parameters from 10 consecutive action potentials were averaged.

\section{Voltage clamp recordings of $I_{\mathrm{K} 1}$}

In a separate series of experiments, the amplitude of the intrinsic $\mathrm{I}_{\mathrm{K} 1}$ of hiPSC-CMs was assessed using the voltage clamp mode of the whole cell patch clamp configuration, using the aforementioned setup. As before, selected cells were beating upon visual inspection. $\mathrm{I}_{\mathrm{K} 1}$ was recorded as a barium sensitive current. First, $5 \mu \mathrm{M}$ nifedipine was washed in to block $\mathrm{Ca}^{2+}$ channels, thus preventing contaminating effects of $\mathrm{Ba}^{2+}$ on calcium currents. Next, $1 \mathrm{mM} \mathrm{BaCl} 2$ was washed in to block inward rectifier channels (Schram et al., 2003). The barium sensitive current was determined by subtracting the current traces recorded in the presence of both nifedipine and $\mathrm{Ba}^{2+}$ from those recorded in the presence of nifedipine. The applied voltage clamp protocol consisted of a series of $100 \mathrm{~ms}$ steps from a holding potential of $-80 \mathrm{mV}$ to a test potential of $-100 \mathrm{mV}$. $\mathrm{I}_{\mathrm{K} 1}$ was defined as the difference current at the end of the $100 \mathrm{~ms}$ step and was normalized for cell size through the membrane capacitance, which amounted to $33 \pm 7$ $\mathrm{pF}($ mean $\pm \mathrm{SEM}, n=7)$. 


\section{Dynamic clamp}

To supply a hiPSC-CM with a controllable virtual $\mathrm{I}_{\mathrm{K} 1}$, we used the dynamic clamp technique (Wilders, 2006). As diagrammed in Figure 1, the membrane potential $\mathrm{V}_{\mathrm{m}}$ of the hiPSC-CM, which is recorded using the perforated patch clamp technique in current clamp mode, is continuously sampled into a Real-Time Linux (RT-Linux) based personal computer. The $\mathrm{V}_{\mathrm{m}}$-dependent current $\mathrm{I}_{\mathrm{K} 1}$ is computed and a command potential generated that, combined with a command potential for any stimulus current $\mathrm{I}_{\text {stim }}$, is sent to the patch clamp amplifier to inject this current into the hiPSC-CM. The virtual $\mathrm{I}_{\mathrm{K} 1}$ is updated at a rate of $25 \mathrm{kHz}$ and both $\mathrm{V}_{\mathrm{m}}$ and the injected current $\mathrm{I}_{\text {in }}$ are stored at a rate of $4 \mathrm{kHz}$ on the standard Apple Macintosh G4 laboratory computer for offline analysis using custom software.

Three types of wild-type (WT) I I 1 models were used: "Kir2.1" based on a fit to data from Kir2.1 channels expressed in HEK-293 cells by Dhamoon et al. (2004), "TNNP" as used in the human ventricular cell model by ten Tusscher et al. (2004), and "Bett" as used by Bett et al. (2013) in their "electronic expression" of $\mathrm{I}_{\mathrm{K} 1}$ in hiPSC-CMs. The current-voltage relationships of these $\mathrm{I}_{\mathrm{K} 1}$ models, all scaled to a peak outward current density of $1 \mathrm{pA} / \mathrm{pF}$, are shown in Figure 2A.

The mathematical equation for the "Kir2.1" current-voltage relationship of Figure $2 \mathrm{~A}$ reads:

$$
I_{K 1}=0.12979 \times\left(\frac{V_{m}-E_{K}}{1.0+e^{\left(0.093633 \times\left(V_{m}+72\right)\right)}}\right)
$$

In this equation, in which the rectification properties of $\mathrm{I}_{\mathrm{K} 1}$ are implemented through a Boltzmann equation, $\mathrm{I}_{\mathrm{K} 1}$ is in $\mathrm{pA} / \mathrm{pF}$ and $\mathrm{V}_{\mathrm{m}}$ is in $\mathrm{mV}$. $\mathrm{E}_{\mathrm{K}}$ is the Nernst potential for potassium, which amounts to $-86.9 \mathrm{mV}$ in our experimental setting.

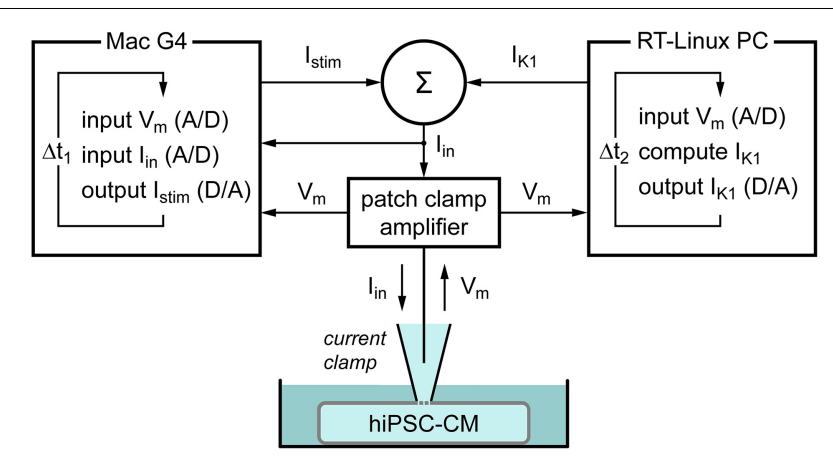

FIGURE 1 | Diagram of the experimental setup. The membrane potential $\left(V_{m}\right)$ of a single human induced pluripotent stem cell derived cardiomyocyte (hiPSC-CM) is recorded using the perforated patch clamp technique in current clamp mode. The injected current $\left(l_{\text {in }}\right)$ is the sum of a stimulus current $\left(I_{\text {stim }}\right)$ and a virtual inward rectifier potassium current $\left(I_{K_{1}}\right)$, which is computed in real time, based on the recorded value of $V_{m}$ (dynamic clamp). The stimulus protocol is run on an Apple Macintosh G4 computer (left), whereas a Real-Time Linux (RT-Linux) based PC is used for the continuous computation of $\mathrm{I}_{\mathrm{K} 1}$ (right). Sample rates are 4 and $25 \mathrm{kHz}$, respectively $\left(\Delta t_{1}=0.25 \mathrm{~ms}\right.$ and $\left.\Delta t_{2}=40 \mu \mathrm{s}\right)$.
The equation for the "TNNP" current-voltage relationship of Figure 2A reads:

$$
I_{K 1}=0.54419 \times G_{K 1} \times \sqrt{\frac{K_{\mathrm{o}}}{5.4}} \times x_{K 1 \infty} \times\left(V_{m}-E_{K}\right)
$$

This is the equation for $\mathrm{I}_{\mathrm{K} 1}$ taken from the ten Tusscher et al. (2004) human ventricular cell model with a scaling factor of 0.54419 to arrive at a peak outward current density of $1 \mathrm{pA} / \mathrm{pF}$. $\mathrm{G}_{\mathrm{K} 1}$ denotes the maximal $\mathrm{I}_{\mathrm{K} 1}$ conductance of $5.405 \mathrm{nS} / \mathrm{pF}$ and $\mathrm{K}_{\mathrm{o}}$ is the extracellular $\mathrm{K}^{+}$concentration of $5.4 \mathrm{mM}$, whereas $\mathrm{x}_{\mathrm{K} 1 \infty}$ is

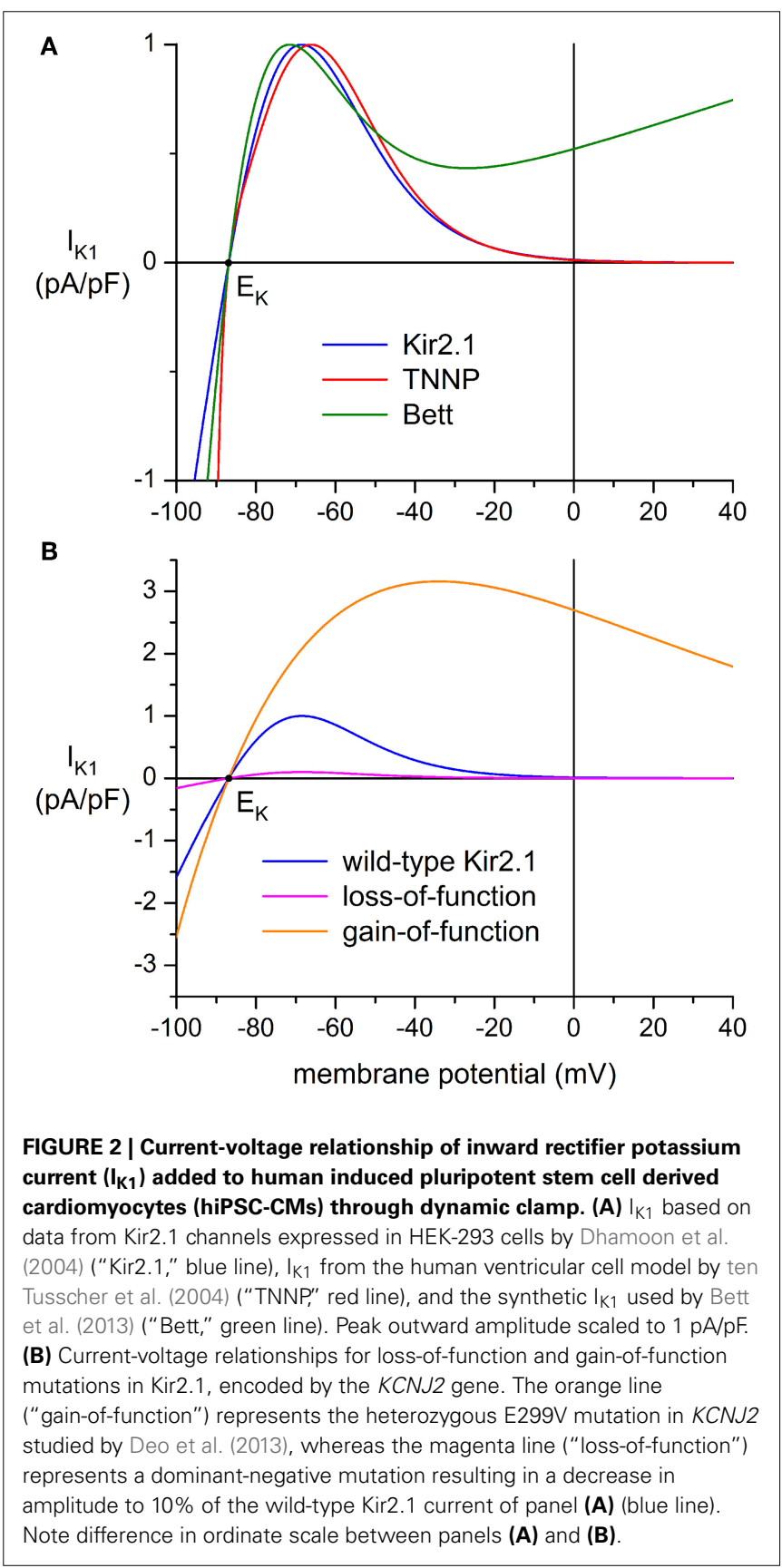


defined through:

$$
\begin{gathered}
x_{K 1 \infty}=\frac{\alpha_{K 1}}{\alpha_{K 1}+\beta_{K 1}} \\
\alpha_{K 1}=\frac{0.1}{1+e^{0.06\left(V_{m}-E_{K}-200\right)}} \\
\beta_{K 1}=\frac{3 e^{0.0002\left(V_{m}-E_{K}+100\right)}+e^{0.1\left(V_{m}-E_{K}-10\right)}}{1+e^{-0.5\left(V_{m}-E_{K}\right)}}
\end{gathered}
$$

The equation for the "Bett" current-voltage relationship of Figure 2A reads:

$$
\begin{aligned}
I_{K 1}= & 0.587557 \times\left(0.5 \times\left(\frac{V_{m}-E_{K}}{1+e^{\left(0.0896\left(V_{m}-E_{K}\right)\right)}}\right)+0.01 \times\right. \\
& \left.\left(V_{m}-E_{K}\right)\right)
\end{aligned}
$$

In the original equation of Bett et al. (2013), $\mathrm{E}_{\mathrm{K}}$ was set to $-85 \mathrm{mV}$ and a potentiometer was used to generate a standard $\mathrm{I}_{\mathrm{K} 1}$ amplitude of $150 \mathrm{pA}$ at $-75 \mathrm{mV}$, independent of cell size. Here, we used the equation of Bett et al. (2013) with the computed $\mathrm{E}_{\mathrm{K}}$ of $-86.9 \mathrm{mV}$ and a scaling factor of 0.587557 to arrive at a peak outward current density of $1 \mathrm{pA} / \mathrm{pF}$. In contrast with the above "Kir2.1" and "TNNP" equations, the "Bett" equation contains a linear part, which explains the shape of the current-voltage relationship at membrane potentials $>-20 \mathrm{mV}$, for which the non-linear part approaches zero.

Another two I I 1 models were used to simulate loss-of-function and gain-of-function mutations in the Kir2.1 encoding KCNJ2 gene. A dominant-negative mutation resulting in a reduction in $\mathrm{I}_{\mathrm{K} 1}$ to $10 \%$ of wild-type control was used to simulate commonly observed functional effects of mutations associated with Andersen-Tawil syndrome type 1 (Nguyen et al., 2013), whereas a heterozygous gain-of-function mutation was based on the $\mathrm{E} 299 \mathrm{~V}$ mutation in KCNJ2 that is associated with short QT syndrome type 3. Comprehensive data on this mutation were obtained by Deo et al. (2013).

The dominant-negative mutation in KCNJ2 was simulated by scaling the above wild-type Kir2.1 based $\mathrm{I}_{\mathrm{K} 1}$ by a factor of 0.1 , thus arriving at:

$$
I_{K 1}=0.012979 \times\left(\frac{V_{m}-E_{K}}{1.0+e^{\left(0.093633 \times\left(V_{m}+72\right)\right)}}\right)
$$

This equation results in the "loss-of-function" current-voltage (I-V) relationship of Figure 2B (magenta line). The "gain-offunction" I-V relationship (Figure 2B, orange line) was obtained by fitting a "Kir2.1"-like equation to the data of Deo et al. (2013), which resulted in:

$$
I_{K 1}=0.98765 \times\left(\frac{V_{m}-E_{K}}{1.0+e^{\left(0.020133\left(V_{m}+170.26\right)\right)}}\right)
$$

The scaling factor of 0.98765 followed from the amplitude of the heterozygous mutant Kir2.1 current relative to wild-type Kir2.1 current reported by Deo et al. (2013).
In our dynamic clamp experiments, the hiPSC-CMs were stimulated at $1 \mathrm{~Hz}$ using 3-ms stimuli that ranged from 200 to $800 \mathrm{pA}$ in amplitude. A virtual $\mathrm{I}_{\mathrm{K} 1}$, defined by any of the above equations, was added using the setup of Figure 1. The peak outward amplitude of this $\mathrm{I}_{\mathrm{K} 1}$ was varied between 0 and $10 \mathrm{pA} / \mathrm{pF}$ in steps of 1 or $2 \mathrm{pA} / \mathrm{pF}$. To minimize any time effects, the order of application of $\mathrm{I}_{\mathrm{K} 1}$ models was varied between experiments.

\section{STATISTICS}

Data are presented as mean \pm SEM. Two-Way Repeated Measures ANOVA followed by the Holm-Sidak post-hoc test was used for comparing the different $\mathrm{I}_{\mathrm{K} 1}$ models and different $\mathrm{I}_{\mathrm{K} 1}$ amplitudes. An unpaired $t$-test with Bonferroni correction for multiple comparisons was used to compare action potential parameters of hiPSC-CMs and human ventricular myocytes. Statistical analysis was carried out with SigmaStat 3.5 software. $P<0.05$ was considered statistically significant.

\section{RESULTS}

\section{CHARACTERISTICS OF hiPSC-CMs}

Figure 3 illustrates the morphological and electrophysiological phenotype of our hiPSC-CMs in comparison with that of native human ventricular myocytes (VMs). For these human VMs we used data that we obtained in the course of a previous study (Verkerk et al., 2005).

Whereas native human VMs are elongated and show a clear and regular cross-striated pattern (Figure 3A, left), the hiPSCCMs are relatively small and less well-organized (Figure 3A, right). In the same dish, their appearance can be circular, with a diameter of $\approx 10 \mu \mathrm{m}$, as well as somewhat elongated.

When we made current clamp recordings from our hiPSCCMs using the perforated patch clamp technique, we obtained widely different action potentials (Figures 3B,C). Some cells were visually beating and showed spontaneous electrical activity (Figure 3B). Others were intrinsically quiescent and action potentials could be elicited with $3 \mathrm{~ms}$ rectangular stimulus pulses of typically $400-600 \mathrm{pA}$. With a value of $\approx-50 \mathrm{mV}$ their resting membrane potential was clearly depolarized compared to that of freshly isolated native VMs (Figure 3C, solid lines vs. dashed line). Also, the action potential duration was considerably shorter, even if we take into consideration that our native VMs originate from explanted hearts of patients with end-stage heart failure and thus most likely show a prolonged action potential due to downregulation of repolarizing currents (Tomaselli and Marbán, 1999), including $\mathrm{I}_{\mathrm{K} 1}$ (Beuckelmann et al., 1993).

Figure 3D shows action potential parameters of 9 spontaneously beating hiPSC-CMs (left black bars) as well as 9 native human VMs (right green bars). As already apparent from Figures 3B,C the action potential amplitude (APA) of $73 \pm 9 \mathrm{mV}$ of the hiPSC-CMs is smaller than that of native human VMs and the action potential duration at $90 \%$ repolarization $\left(\mathrm{APD}_{90}\right)$ of $162 \pm 27 \mathrm{~ms}$ is shorter (Figure 3D, right). Also, the $(\mathrm{dV} / \mathrm{dt})_{\max }$ of $10 \pm 7 \mathrm{~V} / \mathrm{s}$ is much smaller, but this may, at least partly, be due to the depolarized MDP of $-56 \pm 4 \mathrm{mV}$ (Figure 3D, left), because such depolarization may result in almost totally inactivated fast sodium channels and thereby in a strongly reduced $(\mathrm{dV} / \mathrm{dt})_{\max }$ (Berecki et al., 2010). 
A

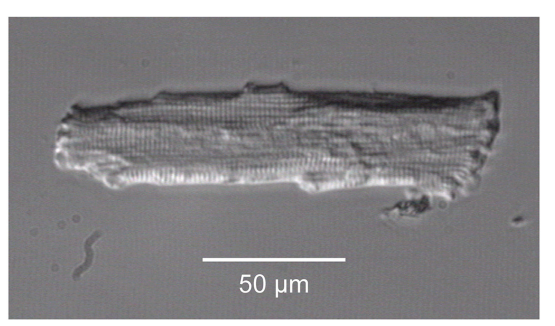

B

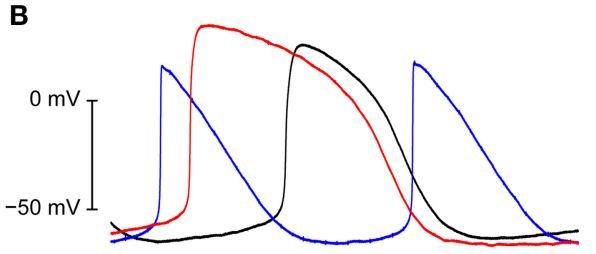

C

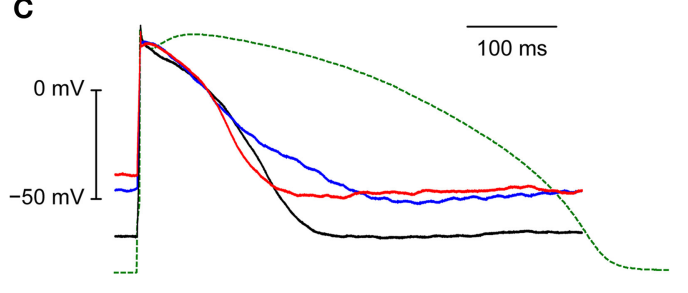

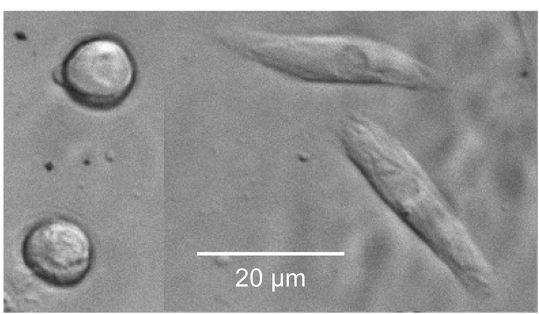

D
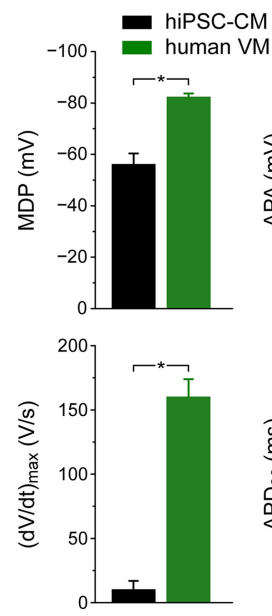

FIGURE 3 | Morphological and electrophysiological phenotype of human induced pluripotent stem cell derived cardiomyocytes (hiPSC-CMs) and native human ventricular myocytes (VMs). (A) Phase-contrast micrographs of a typical human VM (left) and four hiPSC-CMs (right). Differently shaped hiPSC-CMs were present at close distance in the same microscope field. (B) Action potentials of three different spontaneously active hiPSC-CMs. (C) Action potentials of three different intrinsically quiescent hiPSC-CMs upon 1
$\mathrm{Hz}$ stimulation (solid lines) and a typical action potential of a single human VM isolated from a failing heart upon $1 \mathrm{~Hz}$ stimulation (dashed line). (D) Maximum diastolic potential (MDP), maximum upstroke velocity [(dV/dt) max $]$, action potential amplitude (APA) and action potential duration at $90 \%$ repolarization $\left(\mathrm{APD}_{90}\right.$ ) of 9 hiPSC-CMs (left bars) and 9 human VMs (right bars), all stimulated at $1 \mathrm{~Hz}$. Human VMs were isolated from explanted hearts of male patients in end-stage heart failure (Verkerk et al., 2005), $* P<0.05$.

\section{AMPLITUDE OF NATIVE $\mathbf{I}_{\mathbf{K} 1}$}

Because we hypothesized that the depolarized MDP of our hiPSC-CMs was caused by a lack of $\mathrm{I}_{\mathrm{K} 1}$, we carried out voltage clamp experiments to determine the amplitude of $\mathrm{I}_{\mathrm{K} 1}$. In 5 out of 7 cells studied, a detectable $\mathrm{I}_{\mathrm{K} 1}$ was absent. The remaining two cells showed a small $\mathrm{I}_{\mathrm{K} 1}$ with an amplitude of $0.36 \pm 0.14 \mathrm{pA} / \mathrm{pF}$ at $-100 \mathrm{mV}$. To allow for a comparison with the amplitude of the native $\mathrm{I}_{\mathrm{K} 1}$ in isolated mammalian VMs, we carried out a literature search. Results of this search are presented in Figure 4. Results of this search are presented in Figure 4, based on data of Beuckelmann et al. (1993), Liu et al. (1993), Konarzewska et al. (1995), Koumi et al. (1995a,b,c), Kääb et al. (1996), Rozanski et al. (1997), Bailly et al. (1998), Li et al. (1998), Wang et al. (1998), Zaza et al. (1998), Mitcheson and Hancox (1999), Schaffer et al. (1999), Magyar et al. (2000), Pacher et al. (2000), Ishihara et al. (2002), Xiao et al. (2006), Bányász et al. (2007), Jost et al. (2009), Banyasz et al. (2011), Ma et al. (2011), Doss et al. (2012), and Nagy et al. (2013).

According to data from literature, there are large variations in the amplitude of $\mathrm{I}_{\mathrm{K} 1}$. If measured at $-100 \mathrm{mV}$, this amplitude is typically $\approx 10 \mathrm{pA} / \mathrm{pF}$, more or less independent of the considered species (guinea pig, rabbit, dog and human) (Figure 4A). However, canine data vary between $8.9 \pm 1.2$ and $43.2 \pm 1.6$
$\mathrm{pA} / \mathrm{pF}$ ( $n=5$ and $n=43$, respectively) and human data between $3.6 \pm 1.4$ and $32.1 \pm 1.7 \mathrm{pA} / \mathrm{pF}$ ( $n=4$ and $n=14$, respectively). Nevertheless, with the above $0.36 \pm 0.14 \mathrm{pA} / \mathrm{pF}$ and values of $0.8 \pm 0.2(n=6$; Ma et al., 2011) and $2.2 \pm 0.4 \mathrm{pA} / \mathrm{pF}(n=38$; Doss et al., 2012), the amplitude in hiPSC-CMs is considerably smaller than generally observed in human VMs.

In terms of functional relevance, the amplitude of the peak outward $\mathrm{I}_{\mathrm{K} 1}$ (labeled " $\mathrm{B}$ " in Figure 4A, inset) is more relevant than that at $-100 \mathrm{mV}$, which is outside the physiological membrane potential range. However, data on this peak outward current are relatively scarce. As shown in Figure 4B, this peak outward amplitude is typically reached at $\approx-65 \mathrm{mV}$ and amounts to $\approx 2 \mathrm{pA} / \mathrm{pF}$, again more or less independent of species. Human data vary between $0.57 \pm 0.15(n=8$; Bailly et al., 1998) and $2.2 \pm 0.35 \mathrm{pA} / \mathrm{pF}$ ( $n=6$; Wang et al., 1998). Data on peak outward $\mathrm{I}_{\mathrm{K} 1}$ in hiPSC-CMs are limited to a peak value of $1.0 \pm 0.2$ $\mathrm{pA} / \mathrm{pF}$ ( $n=6$; Ma et al., 2011), which was observed at a membrane potential of $-35 \mathrm{mV}$ rather than $\approx-65 \mathrm{mV}$ and is not shown in Figure 4B.

Another discrepancy between studies on $\mathrm{I}_{\mathrm{K} 1}$ in mammalian $\mathrm{VMs}$ is in the shape of the I-V relationship. In some studies, it is reported that $\mathrm{I}_{\mathrm{K} 1}$ approaches zero at potentials $>-20 \mathrm{mV}$, whereas a substantial current is reported in others, as illustrated by the solid and dashed lines in the inset to Figure 4A. In 


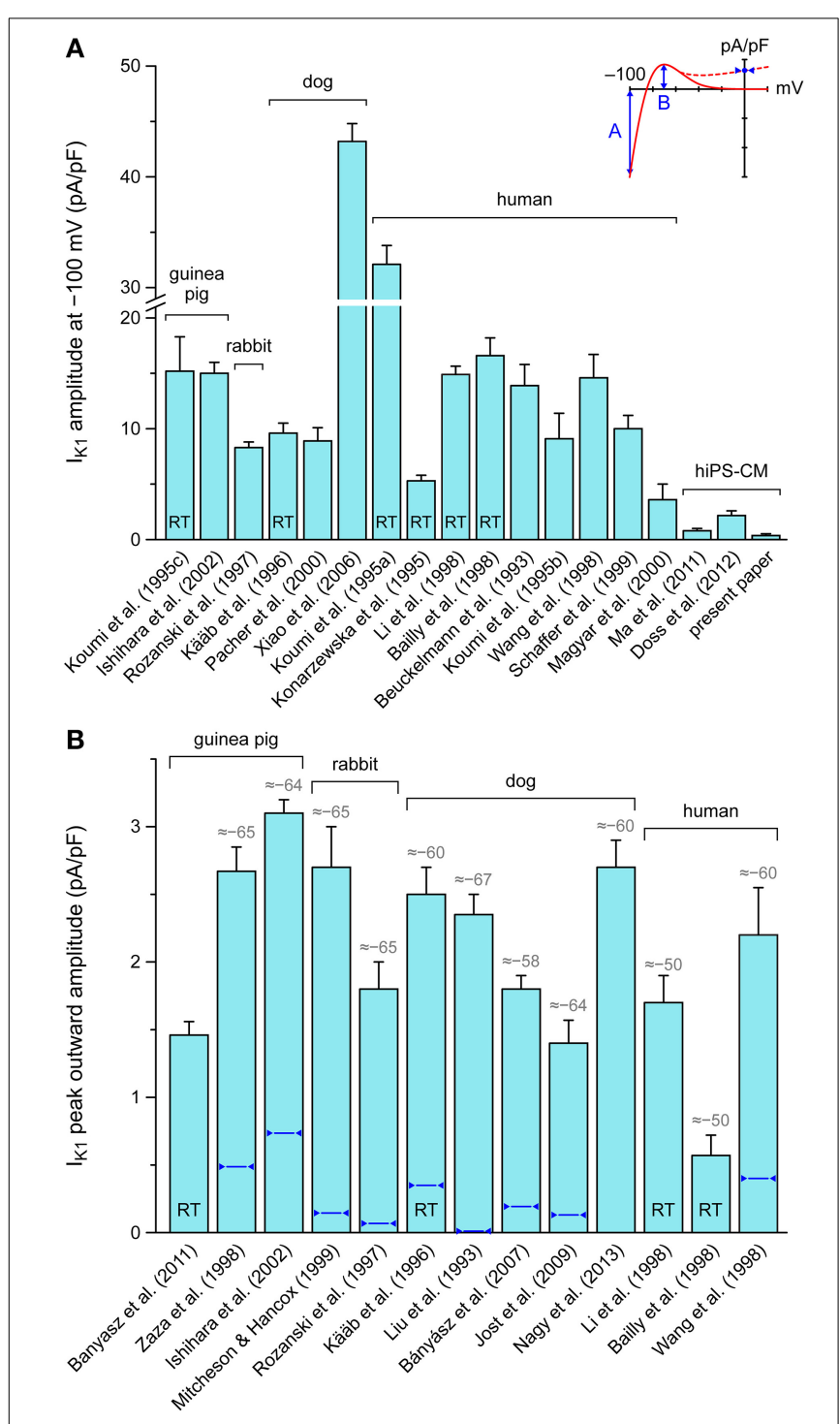

FIGURE 4 | Amplitude of inward rectifier potassium current $\left(I_{K 1}\right)$ in mammalian ventricular myocytes and human induced pluripotent stem cell derived cardiomyocytes (hiPSC-CMs). (A) Amplitude of $I_{K 1}$ at a membrane potential of $-100 \mathrm{mV}$. Note axis break. (B) Amplitude of peak outward $I_{K 1}$. Inset illustrates current-voltage relationship of $I_{K 1}$ with values shown in panels $A$ and $B$. Data are mean \pm SEM obtained at room temperature (bars labeled "RT") or at physiological or close-to-physiological temperature. If data are available, numbers in gray above bars in (B) indicate the membrane potential (in $\mathrm{mV}$ ) at which the peak outward amplitude is reached, whereas dark blue triangles indicate the approximate amplitude at $0 \mathrm{mV}$. Some data are estimated from graphs.

Figure $4 \mathrm{~B}$, the amplitude of $\mathrm{I}_{\mathrm{K} 1}$ at $0 \mathrm{mV}$ is indicated by dark blue triangles. It varies between 0 and $25 \%$ of the peak outward amplitude. In the "Kir2.1," "TNNP," and "Bett" models for $\mathrm{I}_{\mathrm{K} 1}$, this is 1,1 , and 52\%, respectively (see Figure 2A).

\section{ADDITION OF I I 1 THROUGH DYNAMIC CLAMP}

Knowing that the native $\mathrm{I}_{\mathrm{K} 1}$ of our hiPSC-CMs is very small in comparison with that in human VMs (Figure 4), we decided to supply our hiPSC-CMs with an "I $\mathrm{K}_{\mathrm{K} 1}$ boost" through dynamic clamp, injecting a current through the patch clamp pipette with the functional characteristics of the lacking $\mathrm{I}_{\mathrm{K} 1}$, as set out in Materials and Methods Section Dynamic Clamp and diagrammed in Figure 1. Given the uncertainty regarding the "normal" amplitude of $\mathrm{I}_{\mathrm{K} 1}$ in human VMs as well as the shape of its $\mathrm{I}-\mathrm{V}$ relationship, we selected three different models of $\mathrm{I}_{\mathrm{K} 1}$ and varied the amplitude over a wide range.

We injected an in silico $\mathrm{I}_{\mathrm{K} 1}$ into nine different hiPSC-CMs and assessed the effects on the action potential. For each hiPSC-CM, we used each of the "Kir2.1," "TNNP," and "Bett" models for $\mathrm{I}_{\mathrm{K} 1}$, with characteristics detailed in Materials and Methods Section Dynamic Clamp and illustrated in Figure 2. Of note, the I-V relationship of the Kir2.1 and TNNP models is similar to that shown as a solid line in the inset to Figure 4A. In this respect, the Bett model is different, with a substantial current in the membrane potential range of the action potential plateau (Figure 2).

The amplitude of the injected $\mathrm{I}_{\mathrm{K} 1}$ was scaled according to its peak outward current density, which was set to values of 0 (no $\mathrm{I}_{\mathrm{K} 1}$ injected), 1, 2, 4, 6, 8, or $10 \mathrm{pA} / \mathrm{pF}$. Thus, the three different $\mathrm{I}_{\mathrm{K} 1}$ models could be readily compared in the physiological membrane potential range. It should be noted, however, that an identical peak outward current density does not imply an identical amplitude at $-100 \mathrm{mV}$. If, for example, the peak outward current density was set $2 \mathrm{pA} / \mathrm{pF}$, this $\mathrm{I}_{\mathrm{K} 1}$ amplitude at $-100 \mathrm{mV}$ amounted to 3.2, 73.7, and $6.0 \mathrm{pA} / \mathrm{pF}$ for the Kir2.1, TNNP, and Bett models, respectively.

\section{Injection of "Kir2.1" I 1}

Figure 5A shows the native action potential of a hiPSC-CM stimulated at a frequency of $1 \mathrm{~Hz}$ (black trace) and its action potential upon injection of a Kir2.1 $\mathrm{I}_{\mathrm{K} 1}$ with a peak outward density of $1-10 \mathrm{pA} / \mathrm{pF}$. The corresponding injected current is shown in Figure 5B. With an $\mathrm{I}_{\mathrm{K} 1}$ of $1 \mathrm{pA} / \mathrm{pF}$ peak amplitude, the membrane potential becomes hyperpolarized by $\approx 7$ to $-72 \mathrm{mV}$, but the spontaneous diastolic depolarization of the cell is not fully suppressed. Doubling the peak amplitude of the injected $I_{\mathrm{K} 1}$ to 2 $\mathrm{pA} / \mathrm{pF}$ results in a stable RMP of $-79 \mathrm{mV}$ (Figure 5A, blue trace). At this potential, the injected current is $\approx-50 \mathrm{pA}$ (Figure 5B, blue trace), which has the functional effect of an outward, positive membrane current of $50 \mathrm{pA}$. Accordingly, the negative injected current is depicted as an upward deflection.

Upon further increasing the peak outward density of $\mathrm{I}_{\mathrm{K} 1}$ to $4-10 \mathrm{pA} / \mathrm{pF}$, the RMP becomes more negative, reaching an almost steady value near $-84 \mathrm{mV}$, at which the simulated $\mathrm{I}_{\mathrm{K} 1}$ amounts to $\approx 70 \mathrm{pA}$ (Figures 5A,B). The increase in peak current (Figure 5B) causes a more pronounced final repolarization phase of the action potential as well as a shortening in action potential duration (Figure 5A). Also, both $(\mathrm{dV} / \mathrm{dt})_{\max }$ and APA tend to increase, but this is not immediately apparent from Figure 5A.

A statistically significant difference with respect to control (zero $\mathrm{I}_{\mathrm{K} 1}$ addition) is found for the $\mathrm{MDP},(\mathrm{dV} / \mathrm{dt})_{\max }$ and APA starting at a peak outward $\mathrm{I}_{\mathrm{K} 1}$ amplitude of $4 \mathrm{pA} / \mathrm{pF}$ (Figures 5C-E). Significant differences in MDP, (dV/dt) $\max$ and APA are also found between 1 or $2 \mathrm{pA} / \mathrm{pF} \mathrm{I}_{\mathrm{K} 1}$ and higher amplitudes (Figures 5C-E). Injection of $\mathrm{I}_{\mathrm{K} 1}$ with a peak outward density of $4 \mathrm{pA} / \mathrm{pF}$ results in an average $\mathrm{RMP}$ of $-78.0 \pm 1.3 \mathrm{mV}$. For the same $I_{K 1}$ amplitude, a value of $146 \pm 35 \mathrm{~V} / \mathrm{s}$ is found 

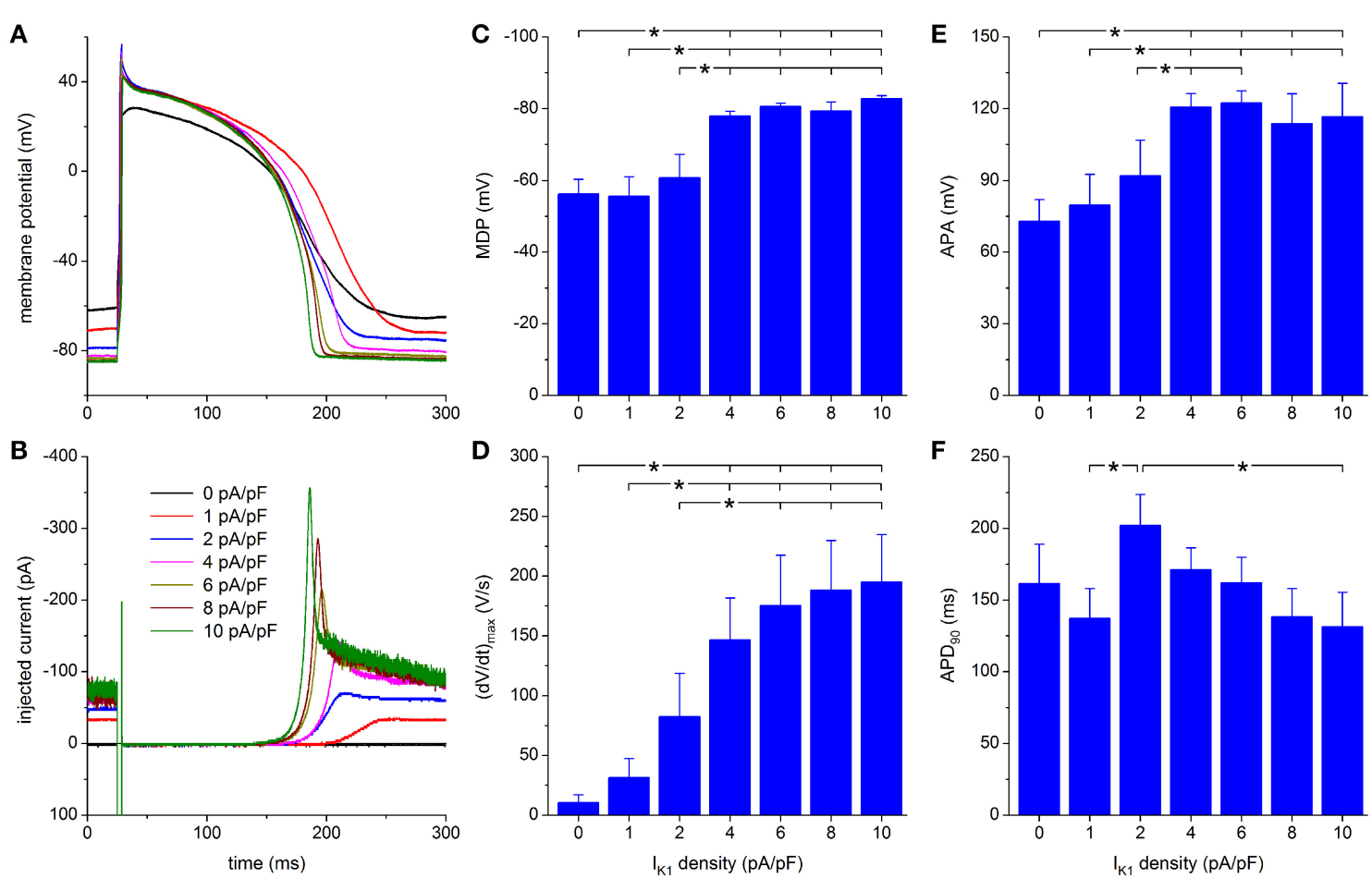

FIGURE 5 | Effect of Kir2.1-based $\mathrm{I}_{\mathrm{K} 1}$ on the action potential of hiPSC-CMs. (A) Action potential of a hiPSC-CM upon injection of simulated $I_{K 1}$, which is computed in real time according to the "Kir2.1" current-voltage relationship of Figure 2A with its peak outward amplitude scaled to 0-10 $\mathrm{pA} / \mathrm{pF}$, as indicated. (B) Corresponding dynamic clamp current injected into the cell. The sharp peak at time $25 \mathrm{~ms}$ is due to the stimulus current of $3 \mathrm{~ms}$ duration and $600 \mathrm{pA}$ amplitude. (C-F) Maximum diastolic potential (MDP), maximum upstroke velocity $\left[(\mathrm{dV} / \mathrm{dt})_{\max }\right]$, action potential amplitude (APA) and action potential duration at $90 \%$ repolarization $\left(A P D_{90}\right.$ ) of 9 hiPSC-CMs at $I_{K 1}$ peak outward amplitudes of $0-10 \mathrm{pA} / \mathrm{pF}, * P<0.05$. for $(\mathrm{dV} / \mathrm{dt})_{\max }$. In line with Figure 5A, Figures 5C,D may suggest a further hyperpolarization of the MDP and an increase in $(\mathrm{dV} / \mathrm{dt})_{\max }$ with increasing peak outward density of $\mathrm{I}_{\mathrm{K} 1}$, but differences were not statistically significant. Figure $5 \mathrm{~F}$ shows a negative trend in $\mathrm{APD}_{90}$, from $202 \pm 22 \mathrm{~ms}$ at $2 \mathrm{pA} / \mathrm{pF}$ to $131 \pm$ $24 \mathrm{~ms}$ at $10 \mathrm{pA} / \mathrm{pF}$, but only the $\mathrm{APD}_{90}$ values at 2 and $10 \mathrm{pA} / \mathrm{pF}$ are statistically significantly different.

\section{Injection of "TNNP" I I 1}

Highly similar results were obtained with the TNNP model of $\mathrm{I}_{\mathrm{K} 1}$, which comes from the widely used ten Tusscher et al. (2004) model of a human ventricular cell. The outward peak is reached at a slightly less negative membrane potential than with the Kir2.1 model ( -66.1 vs. $-68.5 \mathrm{mV}$; Figure 2), but otherwise the $\mathrm{I}-\mathrm{V}$ relationships are largely comparable within the physiological membrane potential range, positive to $\mathrm{E}_{\mathrm{K}}$. Figure 6A shows the effects of injection of the TNNP $I_{K 1}$ on the action potential of the same hiPSC-CM as used for Figure 5A. The corresponding injected current is shown in Figure 6B. With an $\mathrm{I}_{\mathrm{K} 1}$ of $1 \mathrm{pA} / \mathrm{pF}$ peak amplitude, the membrane potential now becomes hyperpolarized by $\approx 6$ to $-71 \mathrm{mV}$. Again, the spontaneous diastolic depolarization is not fully suppressed. A stable RMP of $-77 \mathrm{mV}$ is achieved upon doubling the peak amplitude of the injected $\mathrm{I}_{\mathrm{K} 1}$ to $2 \mathrm{pA} / \mathrm{pF}$ (Figure 6A, blue trace). One may speculate that the slightly smaller hyperpolarization than with the Kir2.1 $\mathrm{I}_{\mathrm{K} 1}(-71$ vs.
$-72 \mathrm{mV}$ and -77 vs. $-79 \mathrm{mV}$ ) reflects the slightly smaller amplitude of the TNNP $\mathrm{I}_{\mathrm{K} 1}$ in this membrane potential range (Figure 2A).

Further observations are highly similar to those with the Kir2.1 $\mathrm{I}_{\mathrm{K} 1}$ model. A stable RMP near $-84 \mathrm{mV}$ is reached upon further increasing the peak outward density of $\mathrm{I}_{\mathrm{K} 1}$ to $4-10 \mathrm{pA} / \mathrm{pF}$ and the increase in peak current causes a more pronounced final repolarization phase of the action potential as well as a shortening in action potential duration (Figures 6A,B). Also, an increase in $(\mathrm{dV} / \mathrm{dt})_{\max }$ and APA is observed.

For both MDP and APA, a statistically significant difference with respect to control (zero $\mathrm{I}_{\mathrm{K} 1}$ addition) occurs at peak outward $\mathrm{I}_{\mathrm{K} 1}$ amplitudes of $2 \mathrm{pA} / \mathrm{pF}$ and higher (Figures 6C,E). For $(\mathrm{dV} / \mathrm{dt})_{\max }$, statistical significance is reached at $4 \mathrm{pA} / \mathrm{pF}$ and higher (Figure 6D). Significant differences in MDP, $(\mathrm{dV} / \mathrm{dt})_{\max }$ and APA are also found between 1 or $2 \mathrm{pA} / \mathrm{pF} \mathrm{I}_{\mathrm{K} 1}$ and higher amplitudes (Figures 6C-E). Injection of $\mathrm{I}_{\mathrm{K} 1}$ with a peak outward density of $4 \mathrm{pA} / \mathrm{pF}$ results in an average RMP of $-78.3 \pm$ $1.2 \mathrm{mV}$. For the same $\mathrm{I}_{\mathrm{K} 1}$ amplitude, a value of $149 \pm 33 \mathrm{~V} / \mathrm{s}$ is found for $(\mathrm{dV} / \mathrm{dt})_{\max }$. More hyperpolarized values for MDP and higher values for $(\mathrm{dV} / \mathrm{dt})_{\max }$ are observed at $6-10 \mathrm{pA} / \mathrm{pF}$, but differences are not statistically significant. As with the Kir2.1 $\mathrm{I}_{\mathrm{K} 1}$, a negative trend in $\mathrm{APD}_{90}$ is observed (Figure 6F), from $208 \pm 20 \mathrm{~ms}$ at $2 \mathrm{pA} / \mathrm{pF}$ to $162 \pm 29 \mathrm{~ms}$ at $10 \mathrm{pA} / \mathrm{pF}$, but it is less pronounced and no statistically significant differences are obtained. 

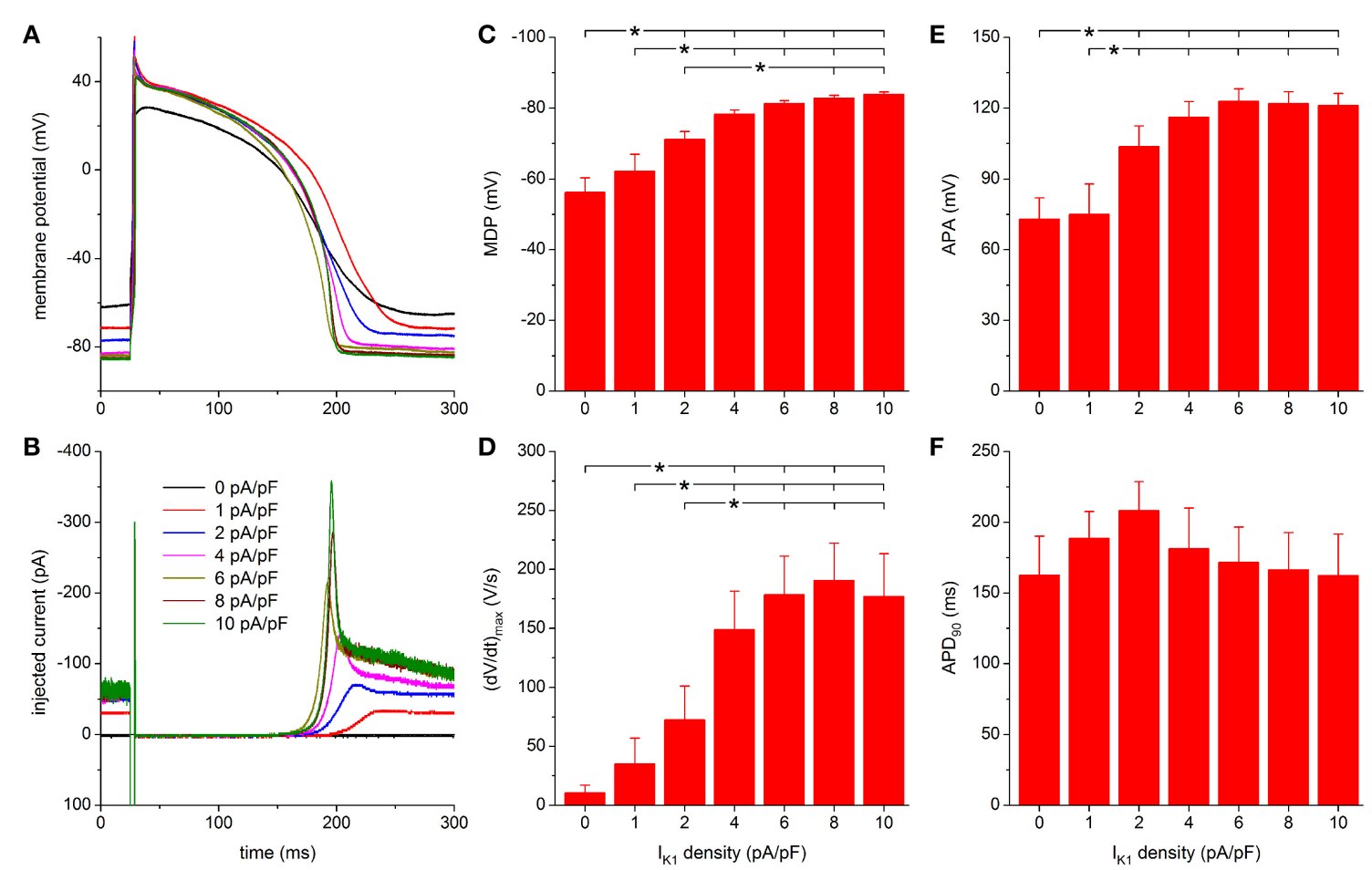

FIGURE 6 | Effect of TNNP-based $\mathrm{I}_{\mathrm{K} 1}$ on the action potential of hiPSC-CMs. (A) Action potential of a hiPSC-CM upon injection of simulated $I_{K 1}$, which is computed in real time according to the "TNNP" current-voltage relationship of Figure 2A with its peak outward amplitude scaled to 0-10 $\mathrm{pA} / \mathrm{pF}$, as indicated. (B) Corresponding dynamic clamp current injected into the cell. The sharp peak at time $25 \mathrm{~ms}$ is due to the stimulus current of $3 \mathrm{~ms}$ duration and $600 \mathrm{pA}$ amplitude. (C-F) Maximum diastolic potential (MDP), maximum upstroke velocity $\left[(\mathrm{dV} / \mathrm{dt})_{\max }\right]$, action potential amplitude (APA) and action potential duration at $90 \%$ repolarization $\left(A P D_{90}\right)$ of 9 hiPSC-CMs at $I_{K 1}$ peak outward amplitudes of $0-10 \mathrm{pA} / \mathrm{pF}, * P<0.05$.

\section{Injection of "Bett" I I 1}

With the Bett model of $\mathrm{I}_{\mathrm{K} 1}$, we obtained different results. This is because of the substantial current at less negative membrane potentials, which is in contrast with the Kir2.1 and TNNP models of $\mathrm{I}_{\mathrm{K} 1}$ (Figure 2A). Figure 7A shows the effects of injection of Bett $\mathrm{I}_{\mathrm{K} 1}$ on the action potential of the same hiPSC-CM as used for Figures 5A, 6A. The corresponding injected current is shown in Figure 7B. The injected current shows a clear non-zero component directly after the stimulus current, which lasts throughout the plateau phase of the action potential and results in a relatively short action potential, due to an early start of repolarization (Figures 7A,B). With an $\mathrm{I}_{\mathrm{K} 1}$ of $1 \mathrm{pA} / \mathrm{pF}$ peak amplitude, the membrane potential becomes hyperpolarized to $-73 \mathrm{mV}$ and this time the spontaneous diastolic depolarization is completely suppressed. Upon doubling the peak amplitude of the injected $\mathrm{I}_{\mathrm{K} 1}$ to $2 \mathrm{pA} / \mathrm{pF}$, a stable RMP of $-80 \mathrm{mV}$ is observed (Figure 7A, blue trace). The early suppression of spontaneous activity and slightly larger hyperpolarization may be attributed to the larger $I_{K 1}$ at membrane potentials negative to $-70 \mathrm{mV}$ than with the Kir2.1 and TNNP models of $\mathrm{I}_{\mathrm{K} 1}$ (Figure 2A).

As with the Kir2.1 and TNNP models of $\mathrm{I}_{\mathrm{K} 1}$, a statistically significant difference with respect to control (zero $\mathrm{I}_{\mathrm{K} 1}$ addition) is found for the MDP, $(\mathrm{dV} / \mathrm{dt})_{\max }$ and APA starting at a peak outward $\mathrm{I}_{\mathrm{K} 1}$ density of $4 \mathrm{pA} / \mathrm{pF}$ (Figures 7C-E). Significant differences in MDP, $(\mathrm{dV} / \mathrm{dt})_{\max }$ and APA are also found between 1 or $2 \mathrm{pA} / \mathrm{pF} \mathrm{I}_{\mathrm{K} 1}$ and higher amplitudes (Figures 7C-E). Injection of $\mathrm{I}_{\mathrm{K} 1}$ with a peak outward density of $4 \mathrm{pA} / \mathrm{pF}$ results in an average RMP of $-79.6 \pm 1.2 \mathrm{mV}$ and an average $(\mathrm{dV} / \mathrm{dt})_{\max }$ of $163 \pm$ $36 \mathrm{~V} / \mathrm{s}$. Slightly more hyperpolarized values for MDP and higher values for $(\mathrm{dV} / \mathrm{dt})_{\max }$ are observed at $6-10 \mathrm{pA} / \mathrm{pF}$, but differences are not statistically significant. As already apparent from Figures 7A,B, the substantial plateau $I_{K 1}$ results in pronounced action potential shortening. In particular, $\mathrm{APD}_{90}$ decreases from $160 \pm 22 \mathrm{~ms}$ at $4 \mathrm{pA} / \mathrm{pF}$ to $99 \pm 24 \mathrm{~ms}$ at $10 \mathrm{pA} / \mathrm{pF}$. However, it should be noted that only the $\mathrm{APD}_{90}$ at $10 \mathrm{pA} / \mathrm{pF}$ differs statistically significantly from the $\mathrm{APD}_{90}$ at some of the lower $\mathrm{I}_{\mathrm{K} 1}$ densities (Figure 7F).

\section{Comparison of $I_{\mathrm{K} 1}$ models}

In Figure 8 the results obtained with the three different models for $I_{K 1}$ are compared, thus concretizing differences between the three models. The typical effects on the action potential of the Kir2.1 and TNNP $\mathrm{I}_{\mathrm{K} 1}$ models, obtained with an $\mathrm{I}_{\mathrm{K} 1}$ peak amplitude of $6 \mathrm{pA} / \mathrm{pF}$ and another hiPSC-CM than in the typical examples of Figures 5-7, are highly similar, but the Bett $\mathrm{I}_{\mathrm{K} 1}$ model causes a shorter action potential (Figure 8A). This shorter action potential is in line with the injected current, which shows a substantial Bett $\mathrm{I}_{\mathrm{K} 1}$ during the early repolarization phase and plateau phase of the action potential (Figure 8B). The average $\mathrm{APD}_{90}$ at an $\mathrm{I}_{\mathrm{K} 1}$ peak amplitude of $6 \mathrm{pA} / \mathrm{pF}$ amounts to $129 \pm 24 \mathrm{~ms}$ for the Bett model vs. $162 \pm 18$ and $171 \pm 25 \mathrm{~ms}$ for the Kir2.1 and TNNP $\mathrm{I}_{\mathrm{K} 1}$ models, respectively (Figure $\mathbf{8 F}$ ). A similar pattern is 

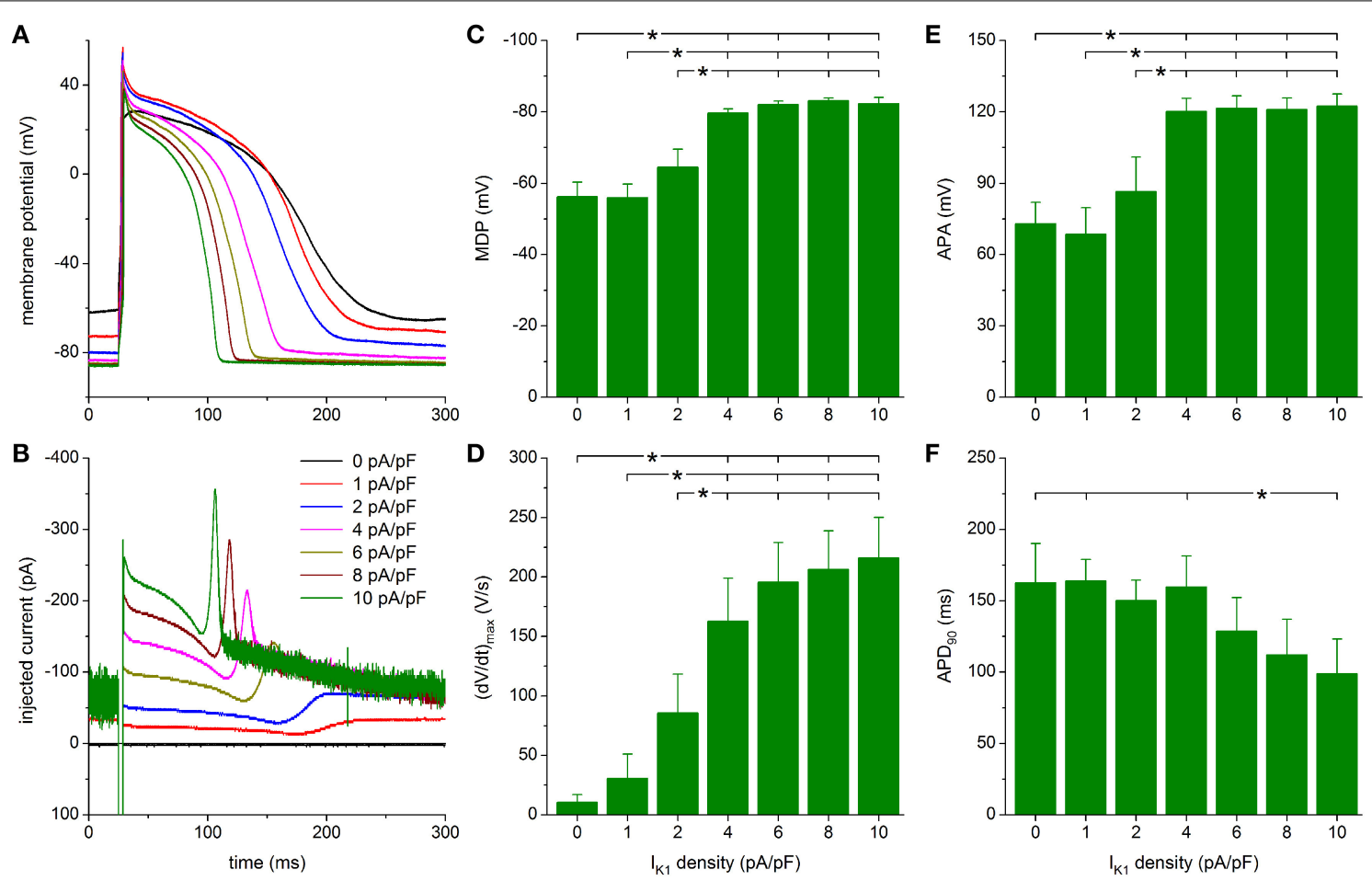

FIGURE 7 | Effect of Bett-based $\mathrm{I}_{\mathrm{K} 1}$ on the action potential of hiPSC-CMs. (A) Action potential of a hiPSC-CM upon injection of simulated $I_{K 1}$, which is computed in real time according to the "Bett" current-voltage relationship of Figure 2A with its peak outward amplitude scaled to $0-10 \mathrm{pA} / \mathrm{pF}$, as indicated. (B) Corresponding dynamic clamp current injected into the cell.
The sharp peak at time $25 \mathrm{~ms}$ is due to the stimulus current of $3 \mathrm{~ms}$ duration and $600 \mathrm{pA}$ amplitude. (C-F) Maximum diastolic potential (MDP), maximum upstroke velocity $\left[(\mathrm{dV} / \mathrm{dt})_{\max }\right]$, action potential amplitude (APA) and action potential duration at $90 \%$ repolarization $\left(\mathrm{APD}_{90}\right.$ ) of 9 hiPSC-CMs at $\mathrm{I}_{\mathrm{K} 1}$ peak outward amplitudes of $0-10 \mathrm{pA} / \mathrm{pF}, * P<0.05$. seen at other $\mathrm{I}_{\mathrm{K} 1}$ peak amplitudes in the $2-10 \mathrm{pA} / \mathrm{pF}$ range. Yet, statistically significant differences in $\mathrm{APD}_{90}$ are mainly observed between the TNNP and Bett $\mathrm{I}_{\mathrm{K} 1}$ models (Figure 8F).

MDP and APA values are highly similar between the three $\mathrm{I}_{\mathrm{K} 1}$ models, except for statistically significant differences found at the lower $\mathrm{I}_{\mathrm{K} 1}$ peak amplitudes of 1 and $2 \mathrm{pA} / \mathrm{pF}$ (Figures 8C,E). Both MDP and APA seem to "saturate," at $\approx-80$ and $\approx 120 \mathrm{mV}$, respectively, for the higher amplitudes of 4-10 $\mathrm{pA} / \mathrm{pF}$. Such saturation is somewhat less apparent for $(\mathrm{dV} / \mathrm{dt})_{\max }$ (Figure 8D), but it reaches typical values of $160-200 \mathrm{~V} / \mathrm{s}$ for each of the models. One may argue that the statistically significant difference in $(\mathrm{dV} / \mathrm{dt})_{\max }$ at $10 \mathrm{pA} / \mathrm{pF}$ reflects the shorter $\mathrm{APD}_{90}$ with the Bett model, which results in a longer interval for recovery of sodium channels between consecutive action potentials.

\section{FUNCTIONAL EFFECTS OF $\mathrm{I}_{\mathrm{K} 1}$ CHANNELOPATHIES}

To explore possible applications of our technique, we assessed both loss-of-function and gain-of-function mutations in Kir2.1, which is encoded by the KCNJ2 gene and is the primary component of the ventricular $\mathrm{I}_{\mathrm{K} 1}$ channel. To simulate a loss-of-function mutation we reduced the wild-type Kir2.1 based $\mathrm{I}_{\mathrm{K} 1}$ to $10 \%$ of control, in line with the functional effects that are commonly observed in case of heterozygous dominant-negative mutations in KCNJ2 associated with the Andersen-Tawil syndrome (type 1; ATS1). As a gain-of-function mutation we chose the heterozygous
E299V mutation, which is associated with the short QT syndrome (type 3; SQT3). The corresponding I-V relationships are shown in Figure 2B, in comparison with the wild-type relationship. Experiments were carried out in a total of 6 hiPSC-CMs and the peak amplitude of the wild-type Kir2.1 was varied over the same $0-10 \mathrm{pA} / \mathrm{pF}$ as before. Figures 9A,B show a typical example at a wild-type peak amplitude of $6 \mathrm{pA} / \mathrm{pF}$ and Figures 9C-F show the average action potential parameters of the 6 hiPSC-CMs. Note that the $0-10 \mathrm{pA} / \mathrm{pF} \mathrm{I}_{\mathrm{K} 1}$ peak amplitude values in Figures $9 \mathrm{C}-\mathrm{F}$ are those for the wild-type case. The corresponding peak amplitudes are $0-1 \mathrm{pA} / \mathrm{pF}$ (10\% of control) and $0-31.6 \mathrm{pA} / \mathrm{pF}$ for the loss-of-function and gain-of-function mutations, respectively, in line with the I-V relationships of Figure 2B.

Simulation of the gain-of-function mutation results in injection of an $\mathrm{I}_{\mathrm{K} 1}$ with such a large amplitude immediately following the action potential upstroke that the action potential is dramatically shortened (Figures 9A,B, orange traces). Such shortening is not limited to the $\mathrm{I}_{\mathrm{K} 1}$ density of $6 \mathrm{pA} / \mathrm{pF}$ in Figures 9A,B. A statistically significant decrease relative to wild-type Kir2.1 occurs at each of the $\mathrm{I}_{\mathrm{K} 1}$ densities $>1 \mathrm{pA} / \mathrm{pF}$ (Figure 9F, right orange bars vs. left blue bars). No statistically significant differences vs. wild-type are observed in $(\mathrm{dV} / \mathrm{dt})_{\max }$ and APA (Figures 9D,E), but RMP is more hyperpolarized, with full suppression of spontaneous depolarization, at 1 and $2 \mathrm{pA} / \mathrm{pF}$ (Figure 9C).

Although not statistically significant, the gain-of-function $(\mathrm{dV} / \mathrm{dt})_{\max }$ seems to become lower than the wild-type $(\mathrm{dV} / \mathrm{dt})_{\max }$ 

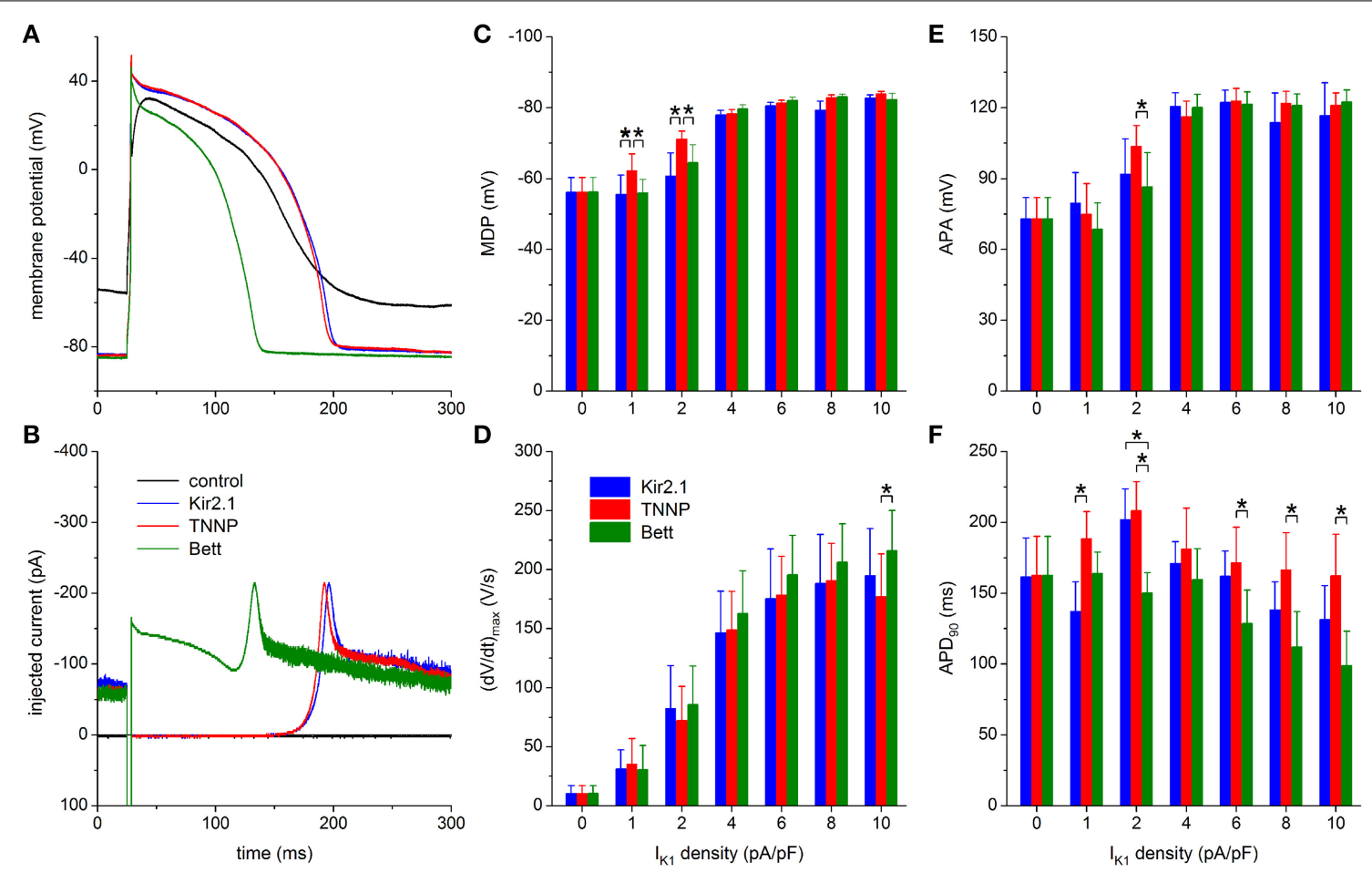

FIGURE 8 | Dynamic clamp with different $\mathbf{I}_{\mathbf{K} 1}$ models. (A) Control action potential of a hiPSC-CM (black trace) and action potential of this cell upon injection of $\mathrm{I}_{\mathrm{K} 1}$ computed in real time according to the "Kir2.1," "TNNP," or "Bett" $\left.\right|_{K 1}$ models of Figure 2A (blue, red, and green lines, respectively), all with a peak outward amplitude of $6 \mathrm{pA} / \mathrm{pF}$. (B) Corresponding dynamic clamp current injected into the cell. The sharp peak at time $25 \mathrm{~ms}$ is due to the stimulus current of 3 ms duration and 600 pA amplitude. (C-F) Comparison of maximum diastolic potential (MDP), maximum upstroke velocity $\left[(\mathrm{dV} / \mathrm{dt})_{\text {max }}\right]$, action potential amplitude (APA) and action potential duration at $90 \%$ repolarization (APD90) of 9 hiPSC-CMs obtained with each of the three $I_{\text {K1 }}$ models. Asterisks indicate statistically significant differences between $I_{\text {K1 }}$ models at each of the applied $I_{\mathrm{K} 1}$ peak outward amplitudes. at higher $I_{K 1}$ densities (Figure 9D). At first sight, this may suggest a lower functional availability of fast sodium channels, despite the longer time for recovery from inactivation at RMP in case of the gain-of-function mutation as a result of the shortened $\mathrm{APD}_{90}$ (Figure 9F). However, the somewhat lowered (dV/dt) $\max$ may be due to the large gain-of-function $\mathrm{I}_{\mathrm{K} 1}$ that flows during the upstroke (Figure 9B), especially at high $\mathrm{I}_{\mathrm{K} 1}$ densities, rather than a lower functional availability of fast sodium channels.

In contrast, the injection of a loss-of-function $\mathrm{I}_{\mathrm{K} 1}$ has only marginal effects, if any, on each of the action potential parameters, if compared to zero current injection (Figures 9C-F). Spontaneous depolarization is not remarkably suppressed throughout the range of $\mathrm{I}_{\mathrm{K} 1}$ densities, which is not surprising since the maximum peak outward amplitude is effectively 1 $\mathrm{pA} / \mathrm{pF}$ because of the reduction to $10 \%$ of wild-type. Compared to wild-type $\mathrm{I}_{\mathrm{K} 1}$ with a peak density $>2 \mathrm{pA} / \mathrm{pF}, \mathrm{MDP}$ is depolarized (Figure 9C), (dV/dt) $\max$ is diminished (Figure 9D) and APA is considerably reduced (Figure 9E), whereas $\mathrm{APD}_{90}$ is virtually unaffected (Figure 9F). Overall, the hiPSC-CM without $\mathrm{I}_{\mathrm{K} 1}$ injection can be regarded as a model for severe ATS1.

\section{DISCUSSION}

In the present study, we increased the expression level of $\mathrm{I}_{\mathrm{K} 1}$ in our hiPSC-CMs by adding in silico $\mathrm{I}_{\mathrm{K} 1}$ using a dynamic patch clamp approach. First, we assessed the effects of the type and magnitude of the added $\mathrm{I}_{\mathrm{K} 1}$. Three different models of $\mathrm{I}_{\mathrm{K} 1}$ were used, i.e., the "Kir2.1," "TNNP," and "Bett" models, and the peak outward density of the inserted $\mathrm{I}_{\mathrm{K} 1}$ was varied between 1 and $10 \mathrm{pA} / \mathrm{pF}$. Next, we assessed the effects of both loss- and gain-of-function mutations in $\mathrm{I}_{\mathrm{K} 1}$ by modifying our in silico $\mathrm{I}_{\mathrm{K} 1}$, thus simulating ATS1 and SQT3, respectively.

\section{CHARACTERISTICS OF hiPSC-CMs}

Among our hiPSC-CMs, we observed both intrinsically quiescent and spontaneously beating cells (Figures 3B,C). However, for the experiments in the present study, we selected spontaneously active hiPSC-CMs, because we expected those to exhibit a smaller $\mathrm{I}_{\mathrm{K} 1}$ than the quiescent ones. We have no data regarding the expression level of native $\mathrm{I}_{\mathrm{K} 1}$ in each individual hiPSC-CM used in our dynamic clamp experiments, but our voltage clamp experiments on the same type of cells demonstrate an almost negligible $\mathrm{I}_{\mathrm{K} 1}$, which is even smaller than in the hiPSC-CMs of Ma et al. (2011) and Doss et al. (2012). It should be kept in mind that the selection of spontaneously beating cells for our experiments may have led to the use of relatively immature hiPSC-CMs.

With an MDP of $-56 \pm 4 \mathrm{mV}$ and an APA of $73 \pm 9 \mathrm{mV}$ (Figure 3D), our hiPSC-CMs exhibit a relatively depolarized 

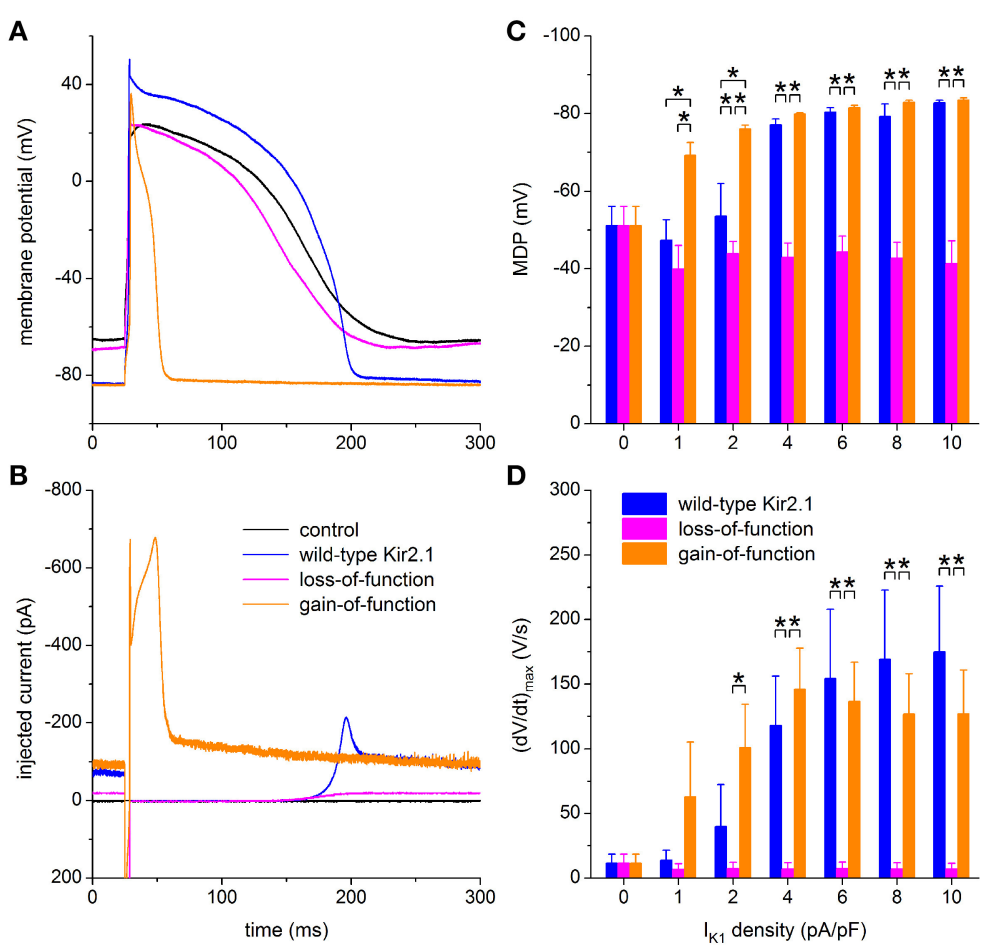

FIGURE 9 | Effect of in silico mutations in Kir2.1 assessed with dynamic clamp. (A) Control action potential of a hiPSC-CM (black trace) and action potential of this cell upon injection of $I_{K 1}$ computed in real time according to the "wild-type Kir2.1," "loss-of-function," or "gain-of-function" I I 1 models of Figure 2B (blue, magenta, and orange lines, respectively), all scaled by a factor of 6 , thus producing a wild-type $I_{K_{1}}$ peak outward amplitude of $6 \mathrm{pA} / \mathrm{pF}$. (B) Corresponding dynamic clamp current injected into the cell. The sharp peak at time $25 \mathrm{~ms}$ is due to the stimulus current of $3 \mathrm{~ms}$ duration and 600 pA amplitude. (C-F) Comparison of maximum diastolic potential (MDP), maximum upstroke velocity $\left[(\mathrm{dV} / \mathrm{dt})_{\max }\right]$, action potential amplitude (APA) and action potential duration at 90\% repolarization (APD90) of 6 hiPSC-CMs obtained with each of the three $\mathrm{I}_{\mathrm{K} 1}$ models. Asterisks indicate statistically significant differences between $I_{K 1}$ models at each of the applied wild-type $\mathrm{I}_{\mathrm{K} 1}$ peak outward amplitudes.
MDP and low APA compared to those observed in other studies on hiPSC-CMs, as summarized in Table 1 of the review by Hoekstra et al. (2012). The $(\mathrm{dV} / \mathrm{dt})_{\max }$ of $10 \pm 7 \mathrm{~V} / \mathrm{s}$ is also low, but that may reflect a low functional availability of sodium channels due to the depolarized MDP, as does the relatively low APA. Most striking, however, is the relatively short $\mathrm{APD}_{90}$ of $162 \pm 27 \mathrm{~ms}$, similar to that of $173.5 \pm 12.2 \mathrm{~ms}(n=16)$ in the hiPSC-CMs of Davis et al. (2012), who selected quiescent rather than spontaneously beating hiPSC-CMs for their action potential recordings, but much shorter than that of $955 \pm 103 \mathrm{~ms}(n=38)$ and $967 \pm 141 \mathrm{~ms}(n=30)$ in the spontaneously beating and quiescent hiPSC-CMs, respectively, of Bett et al. (2013).

We have not made specific attempts to resolve the mechanism underlying the spontaneous activity of our hiPSC-CMs. In our voltage clamp experiments, there were no signs of a functional hyperpolarization-activated "pacemaker current" or "funny current" $\left(\mathrm{I}_{\mathrm{f}}\right)$. This current had been observed in hiPSCCMs by Ma et al. (2011), which are the same type of cells that Bett et al. (2013) used in their dynamic clamp study. However, a strong reduction of $\mathrm{I}_{\mathrm{K} 1}$ is sufficient per se to generate spontaneous activity in VMs, as demonstrated by suppression of $\mathrm{I}_{\mathrm{K} 1}$ through barium block in rabbit and guinea pig papillary muscle (Antoni and Oberdisse, 1965; Aomine, 1989) and isolated guinea pig VMs (Valenzuela and Vassalle, 1989), through viral gene transfer in guinea pig VMs (Miake et al., 2003), and in computer simulations (Doss et al., 2012; Nguyen et al., 2013).

\section{$\mathrm{I}_{\mathrm{K} 1}$ MODEL AND DYNAMIC CLAMP SETUP}

The "Kir2.1" model of Dhamoon et al. (2004) is based on the characteristics of inward rectifier current through Kir2.1 channels expressed in HEK-293 cells. The "TNNP" model stems from the mathematical model of a human ventricular myocyte by ten Tusscher et al. (2004), which is known as the TNNP model. Whereas the I-V relationships of the Kir2.1 and TNNP models are largely similar, the I-V relationship of the "Bett" model, which is based on the "electronic expression" of $\mathrm{I}_{\mathrm{K} 1}$ in hiPSC-CMs by Bett et al. (2013), is different, with a less pronounced rectification (Figure 2A). A common feature of the three $I_{K 1}$ models is the absence of any time dependence of $\mathrm{I}_{\mathrm{K} 1}$, which is in line with the virtually instantaneous kinetics of $\mathrm{I}_{\mathrm{K} 1}$ in the membrane potential range of the ventricular action potential (Dhamoon and Jalife, 2005). It is, however, a straightforward operation to let the dynamic clamp PC generate a time dependent $\mathrm{I}_{\mathrm{K} 1}$.

The setup of Figure 1, which is comparable to that of Bett et al. (2013), is somewhat complicated. In daily practice, it would be preferable to have the same computer both control the patch clamp experiment and generate the in silico $\mathrm{I}_{\mathrm{K} 1}$ rather than 
having two computers perform these tasks and externally summing their command potentials. In case of a time independent current like $\mathrm{I}_{\mathrm{K} 1}$, one may also use a dedicated patch clamp amplifier, such as the Power1401 by Cambridge Electronic Design, to realize the particular dynamic clamp configuration, which is also known as "conductance injection," "reactive current clamp," and "model reference current injection" (Wilders, 2006), and was designated as "real-time current simulator" by Bett et al. (2013).

\section{MAGNITUDE AND RECTIFICATION OF $\mathrm{I}_{\mathrm{K} 1}-$ WHICH MODEL TO USE?}

Data from literature are far from unequivocal regarding the magnitude and rectification of $\mathrm{I}_{\mathrm{K} 1}$ in mammalian VMs (see Figure 4). Differences in recording conditions can only partly explain the observed variety in experimental data. For example, data acquired at room temperature (labeled "RT" in Figure 4) rather than physiological temperature do not consistently show a smaller $\mathrm{I}_{\mathrm{K} 1}$. Yet, from the reported $\mathrm{Q}_{10}$ of $1.5 \pm 0.3$ (mean $\pm \mathrm{SD}$, $n=7$; Kiyosue et al., 1993), one would expect an approximate doubling of the magnitude of $\mathrm{I}_{\mathrm{K} 1}$ upon raising the temperature from RT to physiological values. We refrained from "correcting" the data in Figure 4 for temperature, which may have resulted in an underestimation of the magnitude of $\mathrm{I}_{\mathrm{K} 1}$. A further, also uncorrected underestimation may result from the determination of $\mathrm{I}_{\mathrm{K} 1}$ as a barium dependent current (with widely different $\mathrm{Ba}^{2+}$ concentrations, ranging from $10 \mu \mathrm{M}$ to $1 \mathrm{mM}$ ), because barium block may be incomplete at the membrane potential of peak outward $\mathrm{I}_{\mathrm{K} 1}$ (Bányász et al., 2007). Other issues, apart from technical limitations, that may have had impact on the data in Figure 4, are the dependence of $\mathrm{I}_{\mathrm{K} 1}$ magnitude on extracellular potassium concentration, which is not identical in the listed papers, and differences in corrections for liquid junction potential.

It is difficult to decide on a "physiological" value, or range of values, for the peak outward amplitude of $\mathrm{I}_{\mathrm{K} 1}$. Nevertheless, from the data in Figure 4B, an estimate of $2 \mathrm{pA} / \mathrm{pF}$ seems reasonable. Interestingly, this is close to its value in several human ventricular cell models (Iyer et al., 2004; ten Tusscher et al., 2004; Grandi et al., 2010). Another point of uncertainty is the degree of rectification in the $\mathrm{I}-\mathrm{V}$ relationship of $\mathrm{I}_{\mathrm{K} 1}$ (Figure 4A, inset), although a less pronounced rectification in atrial vs. ventricular CMs is a more or less consistent finding. This variable degree of rectification, which seems attributable to different expression levels of specific Kir2.x subunits (Wang et al., 1998), is why we tested qualitatively different I-V relationships. The Kir2.1 and TNNP I-V relationships may be regarded as "ventricular-like," whereas the I$\mathrm{V}$ relationship of the Bett $\mathrm{I}_{\mathrm{K} 1}$ is more "atrial-like," although it was intended by Bett et al. (2013) as an intermediate I-V relationship that could be "optimized for cell specificity."

From the data in Figures 5-7, we conclude that an outward peak current density of $4-6 \mathrm{pA} / \mathrm{pF}$ is required to establish a stable RMP near $-80 \mathrm{mV}$, associated with a $(\mathrm{dV} / \mathrm{dt})_{\max }$ of $160-170 \mathrm{~V} / \mathrm{s}$ and an APA of $120 \mathrm{mV}$, independent of the $\mathrm{I}_{\mathrm{K} 1}$ model used. Also, around $6 \mathrm{pA} / \mathrm{pF}$, the hiPSC-CM $+\mathrm{I}_{\mathrm{K} 1}$ model system studied does not seem to be sensitive in its action potential parameters. Interestingly, these action potential parameter values are comparable to those of human VMs (Figure 3D), although it should be kept in mind that the data of Verkerk et al. (2005) were obtained with VMs isolated from explanted hearts of patients suffering from end-stage heart failure, which may have led to remodeling of membrane currents and thereby to changes in action potential parameters. The less pronounced rectification of the Bett $\mathrm{I}_{\mathrm{K} 1}$ results in typically shorter $\mathrm{APD}_{90}$ values than with the other two $\mathrm{I}_{\mathrm{K} 1}$ models ( $\approx 145$ vs. $\approx 170 \mathrm{~ms}$ ), as becomes apparent from Figure 8. In either case, $\mathrm{APD}_{90}$ is considerably shorter than that of native human VMs.

Bett et al. (2013) also noted that a stable RMP could be obtained through "electronic expression" of $\mathrm{I}_{\mathrm{K} 1}$. It is, however, difficult to directly compare their findings to ours, not only because of the differences in recording conditions (physiological vs. room temperature, perforated vs. whole cell patch clamp), but also because Bett et al. (2013) did not vary the magnitude of their electronically expressed $\mathrm{I}_{\mathrm{K} 1}$. They used the same magnitude of $\mathrm{I}_{\mathrm{K} 1}$ for all experiments because "this makes for simplicity in application and aspects such as quickly distinguishing between atrial and ventricular cells." The potentiometer in their experimental setup "was set to provide a standard outward current of $150 \mathrm{pA}$ at $-75 \mathrm{mV}$." With their $\mathrm{E}_{\mathrm{K}}$ of $-85 \mathrm{mV}$, this translates to a peak outward $\mathrm{I}_{\mathrm{K} 1}$ of $165 \mathrm{pA}$ near $-70 \mathrm{mV}$. Unfortunately, Bett et al. (2013) did not specify the membrane capacitance of their cells, but an estimate can be made because they used the commercially available iCell cardiomyocytes (Cellular Dynamics, Madison, WI). According to Ma et al. (2011), these cells show a capacitance of $35.0 \pm 2.5 \mathrm{pF}$. If we assume that the hiPSC-CMs used by Bett et al. (2013) had a similar capacitance, the peak outward density of their $\mathrm{I}_{\mathrm{K} 1}$ amounts to $\approx 4.7 \mathrm{pA} / \mathrm{pF}$ (at room temperature), which is within the aforementioned range of 4-6 $\mathrm{pA} / \mathrm{pF}$ required to establish a stable RMP. In a total of 31 "stimulated cells with artificial $\mathrm{I}_{\mathrm{K} 1}$," Bett et al. (2013) observed an RMP of $-84 \pm 0.1 \mathrm{mV}$, an APA of $132 \pm 2 \mathrm{mV}$, and a $(\mathrm{dV} / \mathrm{dt})_{\max }$ of $147 \pm 11 \mathrm{~V} / \mathrm{s}$, which is comparable to our data. However, their $\mathrm{APD}_{90}$, which can only be estimated from graphs, shows a wide variety with typical values around $800 \mathrm{~ms}$ and a maximum near $1800 \mathrm{~ms}$

\section{$\mathrm{I}_{\mathrm{K} 1}$ CHANNELOPATHIES}

As long as hiPSC-CMs express a negligible $\mathrm{I}_{\mathrm{K} 1}$, it is impossible to use hiPSC-CMs derived from ATS1 or SQT3 patients as a model system to study both loss-of-function or gain-of-function mutations in KCNJ2. It is, however, possible to study the effects of such mutations in the setting of hiPSC-CMs through dynamic clamp as we did in our experiments that are summarized in Figure 9. In this way, we were able to demonstrate that the E299V gain-of-function mutation causes a dramatic shortening of the action potential (Figures 9A,F). This cellular observation is in line with the clinically observed exceedingly short QT interval with merging of the QRS complex and T wave (Deo et al., 2013).

As shown in Figure 9, simulation of a dominant-negative lossof-function mutation has only little effect on the intrinsic action potential of our hiPSC-CMs. This suggests that the VMs of ATS1 patients exhibit an unstable and depolarized resting membrane potential. This would result in a reduced functional availability of fast sodium channels and thereby in a lengthening of the QRS interval. However, this is not a common observation in ATS1 patients. On the other hand, such QRS prolongation has 
been found in some but not all mouse models of ATS1 (Nguyen et al., 2013). Hopefully, it will become possible to improve the maturation process - thus "engineering adolescence" (Yang et al., 2014) — and generate more mature hiPSC-CMs, with a clear expression of $\mathrm{I}_{\mathrm{K} 1}$, that allow further research into this intriguing issue.

\section{APPLICATIONS OF VIRTUAL $I_{K 1}$}

hiPSC-CMs are commonly seen as a promising model for the cardiac research field. Spontaneously active hiPSC-CMs, or-less commonly-intrinsically quiescent with a relatively depolarized RMP, are frequently used in patch clamp studies on cardiac ion channelopathies. However, the abnormal action potential profile, and associated abnormal activation of specific membrane currents, may make the hiPSC-CM an untrustworthy model for the study of certain ion channelopathies. In particular, as for example noted by Davis et al. (2012), hiPSC-CMs studies on mutations in the fast sodium channel should be interpreted with care. The aim of the present study was to investigate the feasibility of injecting the missing $\mathrm{I}_{\mathrm{K} 1}$ through dynamic clamp and thus make the hiPSC-CM exhibit a more native ventricular cardiomyocyte-like action potential.

Our study shows that it is feasible to let spontaneously beating hiPSC-CMs exhibit a ventricular-like action potential with a nearphysiological resting membrane potential, maximum upstroke velocity and action potential amplitude through the injection of an in silico $\mathrm{I}_{\mathrm{K} 1}$ with a peak outward density of $4-6 \mathrm{pA} / \mathrm{pF}$. The simulated degree of rectification does primarily affect the action potential duration. We suggest the use of the Kir2.1 model for $\mathrm{I}_{\mathrm{K} 1}$ with a peak outward density near $5 \mathrm{pA} / \mathrm{pF}$. One may prefer the addition of a linear component-as in the Bett model, but with as substantially smaller amplitude (e.g., an amplitude at $0 \mathrm{mV}$ of $10-20 \%$ of peak outward amplitude) - to simulate a less strong rectification, but this is not highly pertinent. As long as research into improving the expression of $\mathrm{I}_{\mathrm{K} 1}$ in hiPSC-CMs is going on, it may be helpful to improve their action potential profile by making them express a virtual $\mathrm{I}_{\mathrm{K} 1}$ through dynamic clamp.

In conclusion, we can state that injection of in silico $\mathrm{I}_{\mathrm{K} 1}$ makes the hiPSC-CM a more reliable model for investigating mechanisms underlying cardiac arrhythmias.

\section{ACKNOWLEDGMENTS}

We thank Maaike Hoekstra and Christiaan C. Veerman for dissociating the hiPSC-CMs used in the present study. Kaomei Guan is supported by the German Research Foundation (DFG, SFB1002 /TP A04).

\section{REFERENCES}

Ambrosini, E., Sicca, F., Brignone, M. S., D’Adamo, M. C., Napolitano, C., Servettini, I., et al. (2014). Genetically induced dysfunctions of Kir2.1 channels: implications for short QT3 syndrome and autism-epilepsy phenotype. Hum. Mol. Genet. 23, 4875-4886. doi: 10.1093/hmg/ddu201

Antoni, H., and Oberdisse, E. (1965). Elektrophysiologische Untersuchungen über die Barium-induzierte Schrittmacher-Aktivität im isolierten Säugetiermyokard. Pflügers Arch. 284, 259-272. doi: 10.1007/BF00362446

Aomine, M. (1989). Effects of amiodarone on barium-induced automatic activity in guinea pig ventricular muscle. Gen. Pharmacol. 20, 35-37. doi: 10.1016/03063623(89)90057-8
Bailly, P., Mouchonière, M., Bénitah, J. P., Camilleri, L., Vassort, G., and Lorente, P. (1998). Extracellular $\mathrm{K}^{+}$dependence of inward rectification kinetics in human left ventricular cardiomyocytes. Circulation 98, 2753-2759. doi: 10.1161/01.CIR.98.24.2753

Banyasz, T., Horvath, B., Jian, Z., Izu, L. T., and Chen-Izu, Y. (2011). Sequential dissection of multiple ionic currents in single cardiac myocytes under action potential-clamp. J. Mol. Cell. Cardiol. 50, 578-581. doi: 10.1016/j.yjmcc.2010.12.020

Bányász, T., Magyar, J., Szentandrássy, N., Horváth, B., Birinyi, P., Szentmiklósi, J., et al. (2007). Action potential clamp fingerprints of $\mathrm{K}^{+}$currents in canine cardiomyocytes: their role in ventricular repolarization. Acta Physiol. 190, 189-198. doi: 10.1111/j.1748-1716.2007.01674.x

Berecki, G., Wilders, R., de Jonge, B., van Ginneken, A. C. G., and Verkerk, A. O. (2010). Re-evaluation of the action potential upstroke velocity as a measure of the $\mathrm{Na}^{+}$current in cardiac myocytes at physiological conditions. PLoS ONE 5:e15772. doi: 10.1371/journal.pone.0015772

Bett, G. C. L., Kaplan, A. D., Lis, A., Cimato, T. R., Tzanakakis, E. S., Zhou, Q., et al. (2013). Electronic "expression" of the inward rectifier in cardiocytes derived from human-induced pluripotent stem cells. Heart Rhythm 10, 1903-1910. doi: 10.1016/j.hrthm.2013.09.061

Beuckelmann, D. J., Näbauer, M., and Erdmann, E. (1993). Alterations of $\mathrm{K}^{+}$currents in isolated human ventricular myocytes from patients with terminal heart failure. Circ. Res. 73, 379-385. doi: 10.1161/01.RES.73.2.379

Cordeiro, J. M., Nesterenko, V. V., Sicouri, S., Goodrow, R. J. Jr., Treat, J. A., Desai, M., et al. (2013). Identification and characterization of a transient outward $\mathrm{K}^{+}$ current in human induced pluripotent stem cell-derived cardiomyocytes. J. Mol. Cell. Cardiol. 60, 36-46. doi: 10.1016/j.yjmcc.2013.03.014

Davis, R. P., Casini, S., van den Berg, C. W., Hoekstra, M., Remme, C. A., Dambrot, C., et al. (2012). Cardiomyocytes derived from pluripotent stem cells recapitulate electrophysiological characteristics of an overlap syndrome of cardiac sodium channel disease. Circulation 125, 3079-3091. doi: 10.1161/CIRCULATIONAHA.111.066092

Deo, M., Ruan, Y., Pandit, S. V., Shah, K., Berenfeld, O., Blaufox, A., et al. (2013). KCNJ2 mutation in short QT syndrome 3 results in atrial fibrillation and ventricular proarrhythmia. Proc. Natl. Acad. Sci. U.S.A. 110, 4291-4296. doi: $10.1073 /$ pnas. 1218154110

Dhamoon, A. S., and Jalife, J. (2005). The inward rectifier current $\left(\mathrm{I}_{\mathrm{K} 1}\right)$ controls cardiac excitability and is involved in arrhythmogenesis. Heart Rhythm 2, 316-324. doi: 10.1016/j.hrthm.2004.11.012

Dhamoon, A. S., Pandit, S. V., Sarmast, F., Parisian, K. R., Guha, P., Li, Y., et al. (2004). Unique Kir2.x properties determine regional and species differences in the cardiac inward rectifier $\mathrm{K}^{+}$current. Circ. Res. 94, 1332-1339. doi: 10.1161/01.RES.0000128408.66946.67

Doss, M. X., Di Diego, J. M., Goodrow, R. J., Wu, Y., Cordeiro, J. M., Nesterenko, V. V., et al. (2012). Maximum diastolic potential of human induced pluripotent stem cell-derived cardiomyocytes depends critically on $\mathrm{I}_{\mathrm{Kr}}$. PLoS ONE 7:e40288. doi: 10.1371/journal.pone.0040288

Gherghiceanu, M., Barad, L., Novak, A., Reiter, I., Itskovitz-Eldor, J., Binah, O., et al. (2011). Cardiomyocytes derived from human embryonic and induced pluripotent stem cells: comparative ultrastructure. J. Cell. Mol. Med. 15, 2539-2551. doi: 10.1111/j.1582-4934.2011.01417.x

Grandi, E., Pasqualini, F. S., and Bers, D. M. (2010). A novel computational model of the human ventricular action potential and Ca transient. J. Mol. Cell. Cardiol. 48, 112-121. doi: 10.1016/j.yjmcc.2009.09.019

Hattori, T., Makiyama, T., Akao, M., Ehara, E., Ohno, S., Iguchi, M., et al. (2012). A novel gain-of-function KCNJ2 mutation associated with short-QT syndrome impairs inward rectification of Kir2.1 currents. Cardiovasc. Res. 93, 666-673. doi: $10.1093 / \mathrm{cvr} / \mathrm{cvr} 329$

Hocini, M., Pison, L., Proclemer, A., Larsen, T. B., Madrid, A., and BlomströmLundqvist, C. (2014). Diagnosis and management of patients with inherited arrhythmia syndromes in Europe: results of the European Heart Rhythm Association Survey. Europace 16, 600-603. doi: 10.1093/europace/euu074

Hoekstra, M., Mummery, C. L., Wilde, A. A. M., Bezzina, C. R., and Verkerk, A. O. (2012). Induced pluripotent stem cell derived cardiomyocytes as models for cardiac arrhythmias. Front. Physiol. 3:346. doi: 10.3389/fphys.2012.00346

Ishihara, K., Yan, D. H., Yamamoto, S., and Ehara, T. (2002). Inward rectifier $\mathrm{K}^{+}$current under physiological cytoplasmic conditions in guinea-pig cardiac ventricular cells. J. Physiol. 540, 831-841. doi: 10.1113/jphysiol.2001. 013470 
Iyer, V., Mazhari, R., and Winslow, R. L. (2004). A computational model of the human left-ventricular epicardial myocyte. Biophys. J. 87, 1507-1525. doi: 10.1529/biophysj.104.043299

Jost, N., Acsai, K., Horváth, B., Bányász, T., Baczkó, I., Bitay, M., et al. (2009). Contribution of $I_{\mathrm{Kr}}$ and $I_{\mathrm{K} 1}$ to ventricular repolarization in canine and human myocytes: is there any influence of action potential duration? Basic Res. Cardiol. 104, 33-41. doi: 10.1007/s00395-008-0730-3

Kääb, S., Nuss, H. B., Chiamvimonvat, N., O’Rourke, B., Pak, P. H., Kass, D. A., et al. (1996). Ionic mechanism of action potential prolongation in ventricular myocytes from dogs with pacing-induced heart failure. Circ. Res. 78, 262-273. doi: 10.1161/01.RES.78.2.262

Kiyosue, T., Arita, M., Muramatsu, H., Spindler, A. J., and Noble, D. (1993). Ionic mechanisms of action potential prolongation at low temperature in guinea-pig ventricular myocytes. J. Physiol. 468, 85-106. doi: 10.1111/j.17481716.2007.01674.x

Knollmann, B. C. (2013). Induced pluripotent stem cell-derived cardiomyocytes: boutique science or valuable arrhythmia model? Circ. Res. 112, 969-976. doi: 10.1161/CIRCRESAHA.112.300567

Konarzewska, H., Peeters, G. A., and Sanguinetti, M. C. (1995). Repolarizing K ${ }^{+}$ currents in nonfailing human hearts: similarities between right septal subendocardial and left subepicardial ventricular myocytes. Circulation 92, 1179-1187. doi: 10.1161/01.CIR.92.5.1179

Koumi, S., Backer, C. L., and Arentzen, C. E. (1995a). Characterization of inwardly rectifying $\mathrm{K}^{+}$channel in human cardiac myocytes: alterations in channel behavior in myocytes isolated from patients with idiopathic dilated cardiomyopathy. Circulation 92, 164-174. doi: 10.1161/01.CIR.92.2.164

Koumi, S., Backer, C. L., Arentzen, C. E., and Sato, R. (1995b). $\beta$-Adrenergic modulation of the inwardly rectifying potassium channel in isolated human ventricular myocytes: alteration in channel response to $\beta$-adrenergic stimulation in failing human hearts. J. Clin. Invest. 96, 2870-2881. doi: 10.1172/JCI118358

Koumi, S., Wasserstrom, J. A., and Ten Eick, R. E. (1995c). $\beta$-Adrenergic and cholinergic modulation of the inwardly rectifying $\mathrm{K}^{+}$current in guinea-pig ventricular myocytes. J. Physiol. 486, 647-659.

Li, G. R., Feng, J., Yue, L., and Carrier, M. (1998). Transmural heterogeneity of action potentials and $I_{\mathrm{to} 1}$ in myocytes isolated from the human right ventricle. Am. J. Physiol. 275, H369-H377.

Lian, X., Zhang, J., Azarin, S. M., Zhu, K., Hazeltine, L. B., Bao, X., et al. (2013). Directed cardiomyocyte differentiation from human pluripotent stem cells by modulating Wnt/ $\beta$-catenin signaling under fully defined conditions. Nat. Protoc. 8, 162-175. doi: 10.1038/nprot.2012.150

Lieu, D. K., Fu, J. D., Chiamvimonvat, N., Tung, K. C., McNerney, G. P., Huser, T., et al. (2013). Mechanism-based facilitated maturation of human pluripotent stem cell-derived cardiomyocytes. Circ. Arrhythm. Electrophysiol. 6, 191-201. doi: 10.1161/CIRCEP.111.973420

Liu, D. W., Gintant, G. A., and Antzelevitch, C. (1993). Ionic bases for electrophysiological distinctions among epicardial, midmyocardial, and endocardial myocytes from the free wall of the canine left ventricle. Circ. Res. 72, 671-687. doi: 10.1161/01.RES.72.3.671

Louch, W. E., Koivumäki, J. T., and Tavi, P. (2015). Calcium signalling in developing cardiomyocytes: implications for model systems and disease. J. Physiol. doi: 10.1113/jphysiol.2014.274712. (in press).

Louch, W. E., Sheehan, K. A., and Wolska, B. M. (2011). Methods in cardiomyocyte isolation, culture, and gene transfer. J. Mol. Cell. Cardiol. 51, 288-298. doi: 10.1016/j.yjmcc.2011.06.012

Ma, J., Guo, L., Fiene, S. J., Anson, B. D., Thomson, J. A., Kamp, T. J., et al. (2011). High purity human-induced pluripotent stem cell-derived cardiomyocytes: electrophysiological properties of action potentials and ionic currents. Am. J. Physiol. Heart Circ. Physiol. 301, H2006-H2017. doi: 10.1152/ajpheart.00694.2011

Magyar, J., Iost, N., Körtvély, Á., Bányász, T., Virág, L., Szigligeti, P., et al. (2000). Effects of endothelin-1 on calcium and potassium currents in undiseased human ventricular myocytes. Pflügers Arch. 441, 144-149. doi: 10.1007/s004240000400

Miake, J., Marbán, E., and Nuss, H. B. (2003). Functional role of inward rectifier current in heart probed by Kir2.1 overexpression and dominant-negative suppression. J. Clin. Invest. 111, 1529-1536. doi: 10.1172/JCI17959

Mitcheson, J. S., and Hancox, J. C. (1999). An investigation of the role played by the E-4031-sensitive (rapid delayed rectifier) potassium current in isolated rabbit atrioventricular nodal and ventricular myocytes. Pflügers Arch. 438, 843-850. doi: $10.1007 /$ s004249900118

Mitcheson, J. S., Hancox, J. C., and Levi, A. J. (1998). Cultured adult cardiac myocytes: future applications, culture methods, morphological and electrophysiological properties. Cardiovasc. Res. 39, 280-300. doi: 10.1016/S00086363(98)00128-X

Nagy, N., Acsai, K., Kormos, A., Sebők, Z., Farkas, A. S., Jost, N., et al. (2013). $\left[\mathrm{Ca}^{2+}\right]_{\mathrm{i}}$-induced augmentation of the inward rectifier potassium current $\left(\mathrm{I}_{\mathrm{K} 1}\right)$ in canine and human ventricular myocardium. Pflügers Arch. 465, 1621-1635. doi: 10.1007/s00424-013-1309-x

Narsinh, K., Narsinh, K. H., and Wu, J. C. (2011). Derivation of human induced pluripotent stem cells for cardiovascular disease modeling. Circ. Res. 108, 1146-1156. doi: 10.1161/CIRCRESAHA.111.240374

Nerbonne, J. M. (2014). Mouse models of arrhythmogenic cardiovascular disease: challenges and opportunities. Curr. Opin. Pharmacol. 15, 107-114. doi: 10.1016/j.coph.2014.02.003

Nguyen, H. L., Pieper, G. H., and Wilders, R. (2013). Andersen-Tawil syndrome: clinical and molecular aspects. Int. J. Cardiol. 170, 1-16. doi: 10.1016/j.ijcard.2013.10.010

Pacher, P., Magyar, J., Szigligeti, P., Bányász, T., Pankucsi, C., Korom, Z., et al. (2000). Electrophysiological effects of fluoxetine in mammalian cardiac tissues. Naunyn Schmiedebergs Arch. Pharmacol. 361, 67-73. doi: 10.1007/s002109900154

Patel, C., Yan, G. X., and Antzelevitch, C. (2010). Short QT syndrome: from bench to bedside. Circ. Arrhythm. Electrophysiol. 3, 401-408. doi: 10.1161/CIRCEP.109.921056

Priori, S. G., Napolitano, C., Di Pasquale, E., and Condorelli, G. (2013). Induced pluripotent stem cell-derived cardiomyocytes in studies of inherited arrhythmias. J. Clin. Invest. 123, 84-91. doi: 10.1172/JCI62838

Priori, S. G., Pandit, S. V., Rivolta, I., Berenfeld, O., Ronchetti, E., Dhamoon, A., et al. (2005). A novel form of short QT syndrome (SQT3) is caused by a mutation in the KCNJ2 gene. Circ. Res. 96, 800-807. doi: 10.1161/01.RES.0000162101.76263.8c

Remme, C. A., Wilde, A. A. M., and Bezzina, C. R. (2008). Cardiac sodium channel overlap syndromes: different faces of SCN5A mutations. Trends Cardiovasc. Med. 18, 78-87. doi: 10.1016/j.tcm.2008.01.002

Rozanski, G. J., Xu, Z., Whitney, R. T., Murakami, H., and Zucker, I. H. (1997). Electrophysiology of rabbit ventricular myocytes following sustained rapid ventricular pacing. J. Mol. Cell. Cardiol. 29, 721-732. doi: 10.1006/jmcc. 1996.0314

Sallam, K., Kodo, K., and Wu, J. C. (2014). Modeling inherited cardiac disorders a cell is worth a thousand genes. Circ. J. 78, 784-794. doi: 10.1253/circj.CJ-140182

Savla, J. J., Nelson, B. C., Perry, C. N., and Adler, E. D. (2014). Induced pluripotent stem cells for the study of cardiovascular disease. J. Am. Coll. Cardiol. 64, 512-519. doi: 10.1016/j.jacc.2014.05.038

Schaffer, P., Pelzmann, B., Bernhart, E., Lang, P., Mächler, H., Rigler, B., et al. (1999). Repolarizing currents in ventricular myocytes from young patients with tetralogy of Fallot. Cardiovasc. Res. 43, 332-343. doi: 10.1016/S00086363(99)00118-2

Schram, G., Pourrier, M., Wang, Z., White, M., and Nattel, S. (2003). Barium block of Kir2 and human cardiac inward rectifier currents: evidence for subunitheteromeric contribution to native currents. Cardiovasc. Res. 59, 328-338. doi: 10.1016/S0008-6363(03)00366-3

Schwartz, P. J., Stramba-Badiale, M., Crotti, L., Pedrazzini, M., Besana, A., Bosi, G., et al. (2009). Prevalence of the congenital long-QT syndrome. Circulation 120, 1761-1767. doi: 10.1161/CIRCULATIONAHA.109.863209

Shimoni, Y., Clark, R. B., and Giles, W. R. (1992). Role of an inwardly rectifying potassium current in rabbit ventricular action potential. J. Physiol. 448, 709-727.

Shinnawi, R., and Gepstein, L. (2014). iPSC cell modeling of inherited cardiac arrhythmias. Curr. Treat. Options Cardiovasc. Med. 16, 331. doi: 10.1007/s11936-014-0331-4

Sinnecker, D., Goedel, A., Laugwitz, K. L., and Moretti, A. (2013). Induced pluripotent stem cell-derived cardiomyocytes: a versatile tool for arrhythmia research. Circ. Res. 112, 961-968. doi: 10.1161/CIRCRESAHA.112.268623

Streckfuss-Bömeke, K., Wolf, F., Azizian, A., Stauske, M., Tiburcy, M., Wagner, S., et al. (2013). Comparative study of human-induced pluripotent stem cells 
derived from bone marrow cells, hair keratinocytes, and skin fibroblasts. Eur. Heart J. 34, 2618-2629. doi: 10.1093/eurheartj/ehs203

Takahashi, K., Tanabe, K., Ohnuki, M., Narita, M., Ichisaka, T., Tomoda, K., et al. (2007). Induction of pluripotent stem cells from adult human fibroblasts by defined factors. Cell 131, 861-872. doi: 10.1016/j.cell.2007. 11.019

ten Tusscher, K. H. W. J., Noble, D., Noble, P. J., and Panfilov, A. V. (2004). A model for human ventricular tissue. Am. J. Physiol. Heart Circ. Physiol. 286, H1573-H1589. doi: 10.1152/ajpheart.00794.2003

Tohyama, S., Hattori, F., Sano, M., Hishiki, T., Nagahata, Y., Matsuura, T., et al. (2013). Distinct metabolic flow enables large-scale purification of mouse and human pluripotent stem cell-derived cardiomyocytes. Cell Stem Cell 12, 127-137. doi: 10.1016/j.stem.2012.09.013

Tomaselli, G. F., and Marbán, E. (1999). Electrophysiological remodeling in hypertrophy and heart failure. Cardiovasc. Res. 42, 270-283. doi: 10.1016/S00086363(99)00017-6

Tristani-Firouzi, M., Jensen, J. L., Donaldson, M. R., Sansone, V., Meola, G., Hahn, A., et al. (2002). Functional and clinical characterization of KCNJ2 mutations associated with LQT7 (Andersen syndrome). J. Clin. Invest. 110, 381-388. doi: $10.1172 / J C I 15183$

Valenzuela, F., and Vassalle, M. (1989). On the mechanism of barium induced diastolic depolarisation in isolated ventricular myocytes. Cardiovasc. Res. 23, 390-399. doi: 10.1093/cvr/23.5.390

Verkerk, A. O., Wilders, R., Veldkamp, M. W., de Geringel, W., Kirkels, J. H., and Tan, H. L. (2005). Gender disparities in cardiac cellular electrophysiology and arrhythmia susceptibility in human failing ventricular myocytes. Int. Heart $\mathrm{J}$. 46, 1105-1118. doi: 10.1536/ihj.46.1105

Verkerk, A. O., den Ruijter, H. M., Bourier, J., Boukens, B. J., Brouwer, I. A., Wilders, R., et al. (2009). Dietary fish oil reduces pacemaker current and heart rate in rabbit. Heart Rhythm 6, 1485-1492. doi: 10.1016/j.hrthm.2009.07.024

Wang, Z., Yue, L., White, M., Pelletier, G., and Nattel, S. (1998). Differential distribution of inward rectifier potassium channel transcripts in human atrium versus ventricle. Circulation 98, 2422-2428. doi: 10.1161/01.CIR.98.22.2422

Watanabe, H., Yang, T., Stroud, D. M., Lowe, J. S., Harris, L., Atack, T. C., et al. (2011). Striking in vivo phenotype of a disease-associated human SCN5A mutation producing minimal changes in vitro. Circulation 124, 1001-1011. doi: 10.1161/CIRCULATIONAHA.110.987248
Wilders, R. (2006). Dynamic clamp: a powerful tool in cardiac electrophysiology. J. Physiol. 576, 349-359. doi: 10.1113/jphysiol.2006.115840

Xiao, L., Zhang, L., Han, W., Wang, Z., and Nattel, S. (2006). Sex-based transmural differences in cardiac repolarization and ionic-current properties in canine left ventricles. Am. J. Physiol. Heart Circ. Physiol. 291, H570-H580. doi: 10.1152/ajpheart.01288.2005

Yang, X., Pabon, L., and Murry, C. E. (2014). Engineering adolescence: maturation of human pluripotent stem cell-derived cardiomyocytes. Circ. Res. 114, 511-523. doi: 10.1161/CIRCRESAHA.114.300558

Zaza, A., Rocchetti, M., Brioschi, A., Cantadori, A., and Ferroni, A. (1998). Dynamic $\mathrm{Ca}^{2+}$-induced inward rectification of $\mathrm{K}^{+}$current during the ventricular action potential. Circ. Res. 82, 947-956. doi: 10.1161/01.RES.82. 9.947

Zhang, J., Wilson, G. F., Soerens, A. G., Koonce, C. H., Yu, J., Palecek, S. P., et al. (2009). Functional cardiomyocytes derived from human induced pluripotent stem cells. Circ. Res. 104, e30-e41. doi: 10.1161/CIRCRESAHA.108. 192237

Conflict of Interest Statement: The authors declare that the research was conducted in the absence of any commercial or financial relationships that could be construed as a potential conflict of interest.

Received: 08 December 2014; paper pending published: 22 December 2014; accepted: 07 January 2015; published online: 03 February 2015.

Citation: Meijer van Putten RME, Mengarelli I, Guan K, Zegers JG, van Ginneken $A C G$, Verkerk $A O$ and Wilders $R$ (2015) Ion channelopathies in human induced pluripotent stem cell derived cardiomyocytes: a dynamic clamp study with virtual $I_{K 1}$. Front. Physiol. 6:7. doi: 10.3389/fphys.2015.00007

This article was submitted to Membrane Physiology and Membrane Biophysics, a section of the journal Frontiers in Physiology.

Copyright (c) 2015 Meijer van Putten, Mengarelli, Guan, Zegers, van Ginneken, Verkerk and Wilders. This is an open-access article distributed under the terms of the Creative Commons Attribution License (CC BY). The use, distribution or reproduction in other forums is permitted, provided the original author(s) or licensor are credited and that the original publication in this journal is cited, in accordance with accepted academic practice. No use, distribution or reproduction is permitted which does not comply with these terms. 